\title{
Simple calculation model for evaluating the fire resistance of unreinforced concrete filled tubular columns
}

\author{
Ana Espinos ${ }^{a}$, Manuel L. Romero ${ }^{\mathrm{a}, *}$, Antonio Hospitaler ${ }^{\mathrm{a}}$ \\ ${ }^{a}$ Instituto de Ciencia y Tecnología del Hormigón (ICITECH), \\ Universitat Politècnica de València, Valencia, Spain \\ * Corresponding author. e-mail address: mromero@mes.upv.es
}

\begin{abstract}
This paper presents a method for calculating the fire resistance of unreinforced axially loaded concrete filled circular hollow section columns, based on the guidelines of Eurocode 4 Part 1.2 for the fire design of composite columns. The different design approaches which are currently available worldwide are reviewed in this paper, focusing in particular on the European code, which is discussed and analysed in depth. Several of the aspects which are nowadays missing or thought to be arguable by researchers in the Eurocode 4 method are studied and on the basis of parametric studies a new proposal is developed, so that designers can easily apply the code in the future. The parametric studies investigate the main factors affecting the fire resistance of unreinforced concrete filled tubular (CFT) columns, such as the outer diameter, the thickness of the steel tube wall, the relative slenderness of the column at room temperature and the fire exposure time, widely covering the range of values which can be found in practice. From the results of these parametric studies, equations for obtaining the equivalent temperatures of steel and concrete are developed, and appropriate flexural stiffness reduction coefficients are integrated in the simple calculation model of Eurocode 4 . The method presented here is valid for centrally loaded circular CFT columns filled with
\end{abstract}


Espinos A, Romero ML, Hospitaler A. Simple calculation model for evaluating the fire resistance of unreinforced concrete filled tubular columns. Eng Struct. 2012;42:231-44. doi: 10.1016/j.engstruct.2012.04.022

unreinforced normal strength concrete, and makes possible the calculation of slender columns, extending the current limitations in buckling length of the European code.

Keywords: Fire resistance; Concrete filled tubular columns; Eurocode 4; Simple calculation model 


\section{NOTATION}

$A_{a, \theta} \quad$ Cross-sectional area of the steel profile at the temperature $\theta$

$A_{c, \theta} \quad$ Cross-sectional area of the concrete at the temperature $\theta$

$A_{m} / V \quad$ Section factor

CFT Concrete filled tube

$D$

Outer diameter of the circular section

$E_{a, \theta}$

Modulus of elasticity of steel at the temperature $\theta$

$E_{c, \theta}$

Tangent modulus of concrete at the temperature $\theta$

$E_{c, s e c, \theta}$

Secant modulus of concrete at the temperature $\theta$

$(E I)_{f i, e f f}$

Effective flexural stiffness in the fire situation

EC4

Eurocode 4

$f_{c}$

Compressive cylinder strength of concrete at room temperature

$f_{y}$

Yield strength of structural steel at room temperature

$I_{a, \theta}$

Second moment of area of the steel profile at the temperature $\theta$

$I_{c, \theta}$

Second moment of area of the concrete at the temperature $\theta$

$k_{i, \theta}$

Reduction factor for a material property at elevated temperature

$L$

Length of the column

$\ell_{\theta}$

Buckling length of the column in the fire situation

$N$

Applied axial load

$\mathrm{NF}$

French National Annex to Eurocode 4 Part 1-2

$N_{f i, c r}$

Elastic critical load in the fire situation

$N_{f i, p l, R d}$

Design cross-sectional plastic resistance to axial compression in fire

Design axial buckling load of the column in the fire situation

Standard fire resistance

Thickness of the steel tube

$\alpha$

Imperfection factor for the buckling curves

$\theta$

Temperature

$\bar{\lambda}$

Relative slenderness of the column at room temperature

$\bar{\lambda}_{\theta}$

$\xi$

Relative slenderness of the column in the fire situation

Relative error

$\varphi_{i, \theta}$

Reduction coefficient to make allowance for the effect of thermal stresses

Member slenderness reduction factor $\left(\chi=N_{f i, R d} / N_{f i, p l, R d}\right)$ 


\section{INTRODUCTION}

The fire resistance of the structural elements is one of the factors that must be taken into account during the design process of a building. Depending on several factors related to the future use and characteristics of the building itself, the required fire resistance time will be higher or lower, ranging from 30 to 180 minutes. Therefore, calculation tools are sought by designers in order to obtain an estimation of the fire resistance that the different structural elements within the building can achieve, or conversely to be able to determine the minimum dimensions of the structural member which fulfil the required fire resistance period.

In particular, the interest in the use and development of simple methods for calculating the fire resistance of concrete filled tubular (CFT) columns is growing, due to the increased usage of this structural typology.

Authors as Zhao et al. [1] or Rush et al. [2] have reviewed the current methods that exist for calculating the fire resistance of CFT columns. Several codes are in use nowadays, which are a result of numerical and experimental investigations carried out by the main groups working in this field of research.

The Chinese Code DBJ13-51 [3] establishes an equation to calculate the thickness of the external fire protection required to achieve a certain fire resistance time and is based on a research carried out by Han et al. [4] [5]. Also a method for calculating the ultimate strength of unprotected concrete filled steel tubular columns subjected to standard fire was developed by this research group [4].

Another approach, which is in use in North America, was developed by Kodur and coworkers [6] [7] [8] at the National Research Council of Canada (NRCC) and has been incorporated into the National Building Code of Canada [9], ASCE/SFPE 29-99 [10], ACI 216 [11] and AISC Steel Design Guide 19 [12]. This approach consists of a single design equation which includes the main parameters affecting the fire resistance of CFT columns. 
Other design equations in use presently include the one in the design guide manual for CFT columns published by the Association of New Urban Housing Technology (ANUHT) in Japan [13] [14].

In Europe, the most extended methods for calculating the fire resistance of CFT columns are those included in EN 1994-1-2 [15], comprising three levels of design: a) tabulated data, b) simple calculation models and c) advanced calculation models. Option a) is available in Clause 4.2.3.4 in the form of a selection table which provides the minimum crosssectional dimensions and reinforcement that a CFT column must have in order to achieve a rated standard fire resistance time under a certain load level. This approach is the most simplistic and its results are highly conservative as pointed out by Rush et al. [2]. Option b), simple calculation models, are the most widespread, and amongst them a full method is presented for calculating the fire resistance of composite columns in Clause 4.3.5.1 based on the elastic buckling theory. A specific method for columns composed of unprotected concrete filled hollow sections is also given in Annex $\mathrm{H}$ of the same code. Finally, advanced calculation models (option c) allow the use of finite element models capable to simulate the realistic fire behaviour of the element based on the modelling of the actual thermo-mechanical problem. This last approach can provide a more accurate approximation of the behaviour, but is generally out of reach of practitioners and often due to limited time or resources it is only applied to very specific design situations.

Authors as Wang [16] [17] [18], Leskela [19], Aribert et al. [20], Ribeiro et al. [21] and Espinos et al. [22] [23] have focused on the study of the simple calculation model in EC4 (option b). Because of the complexity of the specific method in Annex $\mathrm{H}$ and after having been proved that it produces unsafe results for slender columns [16] [20], authors are more inclined to follow the general principles in Clause 4.3.5.1, which cover all types of composite columns. However, in the case of CFT columns, only a few studies have been carried out so 
far to investigate the applicability of the general method in Clause 4.3.5.1. The work by the CTICM group in France [20] [24] has led to the rules published in the French National Annex to EN 1994-1-2 [25]. The authors of the present paper have also carried out some previous work in this direction [23].

Several design guides have been developed on the calculation of the fire resistance of CFT columns, amongst which one can find the Corus Tubes guide [26] and the CIDECT guide [27]. In the latter of these guides, practitioners can find a number of design charts valid for the more commonly used cross-sectional dimensions, where the load bearing capacity of the column for a certain fire exposure time is given as a function of its buckling length, crosssectional dimensions and percentage of reinforcement. Nevertheless, the number of charts available in the technical guides is limited and it would be rather desirable to have a unique and robust method which would be easy to use by designers and readily implemented in any design software.

In this paper, the current provisions of the simple calculation model in EN 1994-1-2 [15] and their modifications included in the French National Annex [25] are discussed, and by means of the results of an extensive parametric study a new proposal is presented, which improves the accuracy of the method and extends its current field of application. Appropriate values of the flexural stiffness reduction coefficients, missing in the actual version of EN 1994-1-2 for concrete filled tubular columns, are developed in this paper, as well as expressions for the equivalent temperatures of the steel tube and concrete core at different standard fire periods, which will facilitate the fire design of such columns. The proposed method is applicable to unprotected CFT columns of circular shape and filled with normal strength plain concrete. It covers a wide range of column slenderness, with buckling lengths at elevated temperature up to $10 \mathrm{~m}$ (corresponding to relative slenderness values in fire from 0.5 to 4.5 ), diameters from $139.7 \mathrm{~mm}$ to $508 \mathrm{~mm}$ and standard fire classes from R30 to R120. 
The new proposal is verified against experimental results and also compared with other methods available in the literature and which are being used worldwide [4] [6] [13], and finally a design example which illustrates the use of the method is presented.

\section{REVIEW OF EXISTING DESIGN GUIDANCE}

\subsection{Simple calculation model in Annex H of EN 1994-1-2 [15]}

Annex H (informative) of EN 1994-1-2 [15] provides a simple calculation model which is specific for concrete filled hollow sections in fire. In this Annex, it is established that the design axial buckling load can be obtained from the following equilibrium equation:

$N_{f i, R d}(\varepsilon)=N_{f i, c r}(\varepsilon)=N_{f i, p l, R d}(\varepsilon)$

where $N_{f i, R d}(\varepsilon)$ is the design value of the fire resistance of the column in axial compression, $N_{f i, c r}(\varepsilon)$ is the Euler buckling load of the column in the fire situation and $N_{f i, p l, R d}(\varepsilon)$ is the design value of the plastic resistance to axial compression of the cross-section at elevated temperature. In this method, these values correspond to a certain axial strain and therefore to a certain stress distribution within the cross-section, and need to be evaluated through an incremental procedure, until the equilibrium is found.

The procedure is based on increasing the strain in steps until $N_{f i, c r}(\varepsilon)$ and $N_{f i, p l, R d}(\varepsilon)$ are equal, subjected to the condition that the axial strain of all the components of the cross-section is the same. The instantaneous values of the stress and tangent modulus of each material for a particular temperature are used, varying with the strain level.

The CTICM group [24] conducted a numerical investigation which revealed important shortcomings of the tangent method. It was found out that Annex $\mathrm{H}$ produces fire buckling loads which lay on the unsafe side when the relative slenderness of the column at room temperature exceeds 0.4 [20]. These findings have recently led to the inclusion of an 
amendment to the existing Annex $\mathrm{H}$ which states that the relative slenderness of the columns should be limited to $\bar{\lambda} \leq 0.5$ for the use of the method.

The method in Annex H can only be applied to columns with buckling lengths in the fire situation $\ell_{\theta} \leq 4.5 \mathrm{~m}$, diameter of cross-section $140 \mathrm{~mm} \leq D \leq 400 \mathrm{~mm}$, concrete grades C20/25 - C40/50 and standard fire resistance $R \leq 120 \mathrm{~min}$.

\subsection{General method for composite columns in Clause 4.3.5.1 of EN 1994-1-2 [15]}

While the method in Annex $\mathrm{H}$ has revealed to produce unsafe results for slender columns [20] and has duly been criticised because of its complexity, the general calculation method in Clause 4.3.5.1 can be used instead, as it is done for other type of composite columns. In fact, the method in Annex G of the same code for partially encased steel sections follows the general rules given in Clause 4.3.5.1.

In this method, the design value of the resistance of composite columns in axial compression exposed to fire $\left(N_{f i, R d}\right)$ is calculated as:

$N_{f i, R d}=\chi N_{f i, p l, R d}$

where $\chi$ is the reduction coefficient for buckling curve "c" given in Clause 6.3.1.2 of EN 1993-1-1 [28] (obtained from the value of the relative slenderness at elevated temperature) and $N_{f i, p l, R d}$ is the design value of the plastic resistance of the cross-section to axial compression in fire.

The design value of the plastic resistance of the cross-section in fire $\left(N_{f i, p l, R d}\right)$, considering that the column has no reinforcement, is given by:

$$
N_{f i, p l, R d}=\sum_{j}\left(A_{a, \theta} f_{y, \theta}\right) / \gamma_{M, f i, a}+\sum_{m}\left(A_{c, \theta} f_{c, \theta}\right) / \gamma_{M, f i, c}
$$


where $A_{i, \theta}$ is the area of each element of the cross-section to which a certain temperature $\theta$ is attributed and subscripts " $a$ " and " $c$ " refer to the steel profile and concrete core, respectively. $\gamma_{M, f i, i}$ are the partial factors for the materials in the fire situation.

The effective flexural stiffness of the column can be calculated through:

$$
(E I)_{f i, e f f}=\sum_{j}\left(\varphi_{a, \theta} E_{a, \theta} I_{a, \theta}\right)+\sum_{m}\left(\varphi_{c, \theta} E_{c, \mathrm{sec}, \theta} I_{c, \theta}\right)
$$

where $I_{i, \theta}$ is the second moment of area of each element of the cross-section to which a certain temperature $\theta$ is attributed, $\varphi_{i, \theta} \theta$ is a reduction coefficient depending on the effect of thermal stresses and $E_{c, s e c, \theta}$ is the secant modulus of concrete at the temperature $\theta$. For composite columns with partially encased steel sections, the reduction coefficients have been defined in Annex G of EN 1994-1-2 [15]. However, for concrete filled sections, the values of these reduction coefficients still have to be established.

The flexural stiffness reduction coefficients were introduced in this formulation to account for the effect of the self-equilibrated thermal stresses caused by the non-uniform temperature distribution within the composite cross-section and the unequal thermal expansion of steel and concrete [29]. In the absence of predefined values for these coefficients, as it is the case of CFT columns, a common approach in practice is to take them as equal to unity [29]. Only few studies have been carried out so far on the suitable values of the coefficients, those of the CTICM group [20] [24] and that of the authors of this paper [23].

Once the effective flexural stiffness is calculated, the Euler buckling load in the fire situation is obtained:

$N_{f i, c r}=\pi^{2}(E I)_{f i, e f f} / \ell_{\theta}^{2}$

where $\ell_{\theta}$ is the effective length of the column at a certain temperature $\theta$.

The relative slenderness of the column at elevated temperatures is given by: 


$$
\bar{\lambda}_{\theta}=\sqrt{N_{f i, p l, R} / N_{f i, c r}}
$$

where $N_{f i, p l, R}$ is the value of $N_{f i, p l, R d}$ when the material factors are taken as 1.0. This value of the relative slenderness is used to enter to the buckling curve "c", from where the reduction coefficient $\chi$ needed for determining the buckling load is finally obtained.

\subsection{French National Annex to EN 1994-1-2 [25]}

The French National Annex to EN 1994-1-2 (NF EN 1994-1-2/NA) [25] is based on the general method described in Clause 4.3.5.1 of EN 1994-1-2 [15]. In this National Annex, specific values for the flexural stiffness reduction coefficients have been included to account for the effect of the differential thermal stresses within the composite cross-section. These values are a result of an extensive parametric investigation carried out at the CTICM [24]. For the concrete core, a reduction coefficient of 0.8 is specified, resulting in $\varphi_{c, \theta}=1.2$, which includes implicitly the use of the initial tangent modulus of concrete (calculated as $3 / 2$ times the secant modulus, therefore $0.8 \times 3 / 2=1.2$ for direct application over the secant modulus), while for the steel hollow section the value of the reduction coefficient $\varphi_{a, \theta}$ depends on the fire duration and the size ( $B$ or $D)$ of the steel section, according to Clause 4(2) of NF EN 1994-1-2/NA.

The method included in the French National Annex establishes also specific buckling curves with a discontinuity at a certain value of the relative slenderness, called the "transition relative slenderness". This transition value is dependent on the fire exposure time, and is equal to 1.0 for R30 and 1.35 for R60 in the case of unreinforced columns. Before reaching the transition value, the buckling curve follows the shape of the EN 1993-1-1 [28] curves but with a different imperfection factor for the different fire periods $(\alpha=0.21$ for R30 and $\alpha=$ 0.265 for R60). For relative slenderness values above the transition slenderness, the method makes use of specific buckling curves. 
The French method is limited to buckling lengths in the fire situation $\ell_{\theta} / D \leq 30$, concrete grades C20/25 - C60/75, D $\leq 610 \mathrm{~mm}$, and for centrally loaded unreinforced CFT columns a minimum dimension is required depending on the fire resistance class: $D>100$ $\mathrm{mm}$ for R30 and $D>150 \mathrm{~mm}$ for R60. For unreinforced columns longer fire resistance times cannot be evaluated by this method, since a minimum percentage of reinforcement is required for achieving a R90 or higher fire resistance class.

\subsection{Simplified design equation proposed by Kodur [6] [8]}

Kodur [6] [8] proposed a simplified equation based on the results of parametric studies supported by an experimental program carried out in the Institute for Research in Construction, NRCC (Canada) [30] on circular and square concrete filled tubular columns under fire. This approach is used in the United States and Canada after having been incorporated into several building codes [9], [10], [11] and design guides [12].

Kodur's design equation directly provides the fire resistance time of the column in minutes as a function of different parameters such as the concrete strength, the column diameter and effective length, the type of concrete filling, cross-sectional shape and percentage of steel reinforcement.

The fire resistance time of a column can be evaluated by the following equation as a function of the different parameters:

$$
R=f \frac{f_{c}+20}{\ell_{\theta}-1000} D^{2} \sqrt{\frac{D}{N}}
$$

where $R$ is the fire resistance time in minutes, $f_{c}$ is the concrete strength at the age of 28 days in MPa, $D$ is the outside diameter of the column in mm (also applicable to square columns if the width is used instead), $N$ is the applied load in $\mathrm{kN}, \ell_{\theta}$ is the effective buckling length of the column in mm and $f$ is a coefficient which includes the effect of the rest of the parameters, 
given in [6]. This coefficient is tabulated as a function of the type of concrete filling (plain, bar-reinforced or fibre-reinforced concrete), the type of aggregate used (carbonate or siliceous), the percentage of reinforcement, the thickness of the concrete cover, and the crosssectional shape of the column (circular or square).

The applicability of equation (7) is limited to $f_{c}=20-40 \mathrm{MPa}, D=140-410 \mathrm{~mm}, R \leq$ $120 \mathrm{~min}$ and $\ell_{\theta}=2000-4000 \mathrm{~mm}$ for columns without any reinforcement. Therefore, the method cannot be applied to columns with a high slenderness.

\subsection{Strength index formulation proposed by Han [4]}

Han and co-workers [4] proposed a formulation which makes possible to determine the strength index (SI) of CFT columns based on the results of parametric and experimental studies carried out at the Tianjin Fire Research Institute (China). The formulation was obtained by using regression analysis, and is valid for circular hollow steel columns without fire protection, filled with plain concrete. Also columns with external fire protection were investigated, and the design equations developed were incorporated in the Chinese code DBJ13-51 [3]. For simplicity, the formulation of the method has not been transcribed here, but it can be found in [4]. The validity limits of Han's design equation are: $t \leq 180 \mathrm{~min}, D=$ $150-2000 \mathrm{~mm}, f_{y}=200-500 \mathrm{MPa}, f_{c}=20-60 \mathrm{MPa}$ and $\lambda=15-80$ (slenderness ratio defined here as $\lambda=4 L / D)$.

\subsection{Fire resistance design formula used in Japan [13]}

The actual state of the fire design codes in Japan was reviewed by Harada [14]. Regarding concrete-filled steel tubular columns, the Association of New Urban Housing Technology (ANUHT) in Japan published a design guide manual [13] where a simple equation for obtaining the ultimate load of the column under a certain fire period can be found. For circular columns, the expression is as follows: 


$$
\frac{N_{f i, R d}}{A_{c} f_{c}}=\left(5.75 \cdot 10^{-5} \cdot f_{c}^{2.63} \cdot t+1\right)^{-0.214}
$$

where $A_{c}$ is the cross-sectional area of concrete in $\mathrm{mm}^{2}, f_{c}$ is the specified 28 day concrete strength in MPa and $t$ is the fire resistance time in minutes.

\section{NUMERICAL MODEL AND PARAMETRIC STUDIES}

\subsection{Description of the numerical model}

A previously validated numerical model developed by the authors with the finite element analysis package ABAQUS [31] is available. This model is capable to simulate with enough accuracy the fire behaviour of slender concrete filled circular hollow section columns. The details of the model and its validation process are described in [22], where the numerical model was validated against fire tests available in the literature [30]. The average value of the error in the predictions of the fire resistance time, evaluated as test/prediction, was 1.08 with a standard deviation equal to 0.19 . The range of diameters analysed is this validation stage varied between $141.3 \mathrm{~mm}$ and $273.1 \mathrm{~mm}$, and the room temperature relative slenderness of the columns ranged from 0.29 to 0.98 . Recently, a second validation stage of the model was carried out against fire tests performed by the own authors [32], where columns with high relative slenderness and different types of concrete infill were analysed. In this second validation stage, for those columns filled with normal strength concrete, an average error in the predictions equal to 1.09 was obtained, with a 0.16 standard deviation. The cross-sectional dimensions of the columns were constant in this case, while the concrete grade, reinforcement type and load level were varied. The room temperature relative slenderness of the columns tested in this experimental research ranged from 0.61 to 0.88 .

By means of the numerical model, a sequentially coupled thermal-stress analysis can be performed. First, a pure heat transfer analysis is conducted for computing the temperature 
evolution along the column and afterwards a stress/deformation analysis is run for calculating the structural response. Nodal temperatures are stored as a function of time in the heat transfer analysis results and then read into the stress analysis as a predefined field.

The standard ISO-834 [33] fire curve is applied to the exposed surface of the CFT column specimens as a thermal load, through the convection and radiation heat transfer mechanisms. The values recommended in EN 1991-1-2 [34] are used for the main heat transfer parameters. The entire length of the columns is considered to be exposed to the fire. The thermal resistance at the boundary between the steel tube and the concrete core is taken into account through a gap conductance value of $200 \mathrm{~W} / \mathrm{m}^{2} \mathrm{~K}$, as was used in previous investigations [22]. It was proved through a sensitivity analysis that, despite it is known that the gap clearance size and therefore the thermal resistance at the steel-concrete interface vary during the evolution of the fire, a constant value can be assumed obtaining satisfactory results.

Once the thermal problem is solved, a nonlinear stress analysis is subsequently conducted, accounting for the previously calculated nodal temperature-time curves.

The numerical model takes into account an initial out-of-straightness of the columns equal to $L / 1000$, which is a result of a sensitivity analysis carried out in previous investigations [22]. Pin-ended boundary conditions are considered. Owing to symmetry of both the geometry and the boundary conditions, only a quarter of the column needs to be modelled. Fig. 1 shows the finite element mesh for one of the column specimens analysed.

The steel tube and concrete core are meshed using three-dimensional eight-noded solid elements, with a maximum element size of $20 \mathrm{~mm}$, which had been proved to be sufficient to predict with enough accuracy the fire behaviour of CFT columns [22]. The steel end plate is modelled as a discrete rigid part with all nodes coupled to a reference point, located at the column axis. The axial load is applied to the rigid plate through its reference node and 
maintained constant during the fire history. The rigid plate is meshed using four-noded threedimensional bilinear rigid quadrilateral elements, with a maximum element size of $20 \mathrm{~mm}$.

The selected material models are a result of an extensive sensitivity analysis carried out in previous research [22]. For concrete, the stress-strain curves at elevated temperatures proposed by Lie [35] are employed. The high temperature thermal properties for concrete are taken from EN 1992-1-2 [36], except for the thermal expansion coefficient, which is given a value of $\alpha_{c}=6 \times 10^{-6}{ }^{\circ} \mathrm{C}^{-1}$ as recommended by Hong and Varma [37] and subsequently verified by the authors in the sensitivity analysis [22]. For structural steel, the temperature dependent thermal and mechanical properties recommended in EN 1993-1-2 [38] are adopted. A moisture content of $3 \%$ in concrete weight is considered in this research, which is taken into account through a peak value of $2020 \mathrm{~J} / \mathrm{kgK}$ in the specific heat formulation of concrete.

\subsection{Parametric studies}

Parametric studies were performed by means of the numerical model described in the previous section. The main parameters affecting the buckling resistance of unreinforced CFT columns at elevated temperatures were investigated through these parametric studies. The parameters studied are the outer diameter of the column $(D)$, the thickness of the steel tube wall $(t)$, the relative slenderness of the column at room temperature $(\bar{\lambda})$ and the standard fire period $(R)$, widely covering the range of values which can be found in practice. A summary of the cases analysed in this parametric study is shown in Table 1.

The composite sections analysed in this parametric study considered a steel yield strength of $355 \mathrm{MPa}$ as most commonly used, and concrete compressive strength of $30 \mathrm{MPa}$, since this study is limited to normal strength concrete. Six different circular section sizes of commercially available dimensions were employed: 139.7, 193.7, 273, 323.9, 406.4 and 508 mm. For each diameter, two steel tube wall thicknesses were selected: the minimum and maximum commercially available values, although it is noteworthy that the minimum 
thickness was chosen as the first value which produced a class 3 section (thin-walled sections were not included in this study). For each cross-section, five different column lengths were used, corresponding to slenderness values at room temperature of $0.3,0.5,1,1.5$ and 2 . The relative slenderness values of the columns at room temperature were calculated in accordance with Clause 6.7.3.3 of EN 1994-1-1 [39] assuming hinged end conditions. The influence of enhanced concrete confinement was not considered in the room temperature calculations.

The maximum slenderness analysed for each cross-section was selected in such a way that the associated buckling length of the column did not exceed 10 meters, in order to reduce the computational cost of this study. Therefore, the combinations of diameters and member slenderness were as follows: $D=139.7 \mathrm{~mm}(\bar{\lambda}=0.3,0.5,1,1.5,2) ; D=193.7 \mathrm{~mm}(\bar{\lambda}=0.3$, $0.5,1,1.5,2) ; D=273 \mathrm{~mm}(\bar{\lambda}=0.3,0.5,1,1.5) ; D=323.9 \mathrm{~mm}(\bar{\lambda}=0.3,0.5,1) ; D=406.4$ $\mathrm{mm}(\bar{\lambda}=0.3,0.5,1) ; 508 \mathrm{~mm}(\bar{\lambda}=0.3,0.5)$.

For each column, four different standard fire resistance classes were considered: 30, 60, 90 and 120 minutes (hereafter referred to as R30, R60, R90 and R120), which are the common values prescribed in the design codes. Each column specimen employed a different combination of the specified values of the variables shown in Table 1. In total, the number of specimens analysed in this parametric study was 176 .

The procedure employed in this research to calculate the buckling resistances which correspond to the different fire exposure times analysed (30, 60, 90 and 120 minutes) was as follows. In a first step, the fire resistance time of the column was obtained by means of the numerical model under several values of the applied axial load (in general, 10 different values were used), so as to be able to build up a curve of the evolution of the buckling load versus the fire exposure time. In a second step, the value of the buckling load corresponding to the desired standard time (R30, R60, R90 or R120) was obtained from this curve by using linear 
interpolation. Special care was taken in the vicinity of the standard fire times, where the curve was refined, so that the error in the interpolation was minimum.

Fig. 2 explains graphically the process followed for obtaining the buckling resistance of a column at the specified standard fire times. As can be seen, this procedure requires an elevated number of calculations to perform for each column specimen, which limits the extension of this parametric analysis.

\subsection{Analysis of results}

From the results of all the calculations performed in the parametric studies, the numerical buckling coefficient was computed. It was defined as the column axial buckling resistance obtained from the numerical simulation divided by the design value of the crosssectional plastic resistance, both in the fire situation: $\chi^{N U M}=\frac{N_{f i, R d}^{N U M}}{N_{f i, p l, R d}}$. This value was plotted against the relative slenderness at elevated temperature $\bar{\lambda}_{\theta}=\sqrt{N_{f i, p l, R} / N_{f i, c r}}$, calculated as described in Section 2.2 and using reduction coefficients equal to unity. Fig. 3 shows the results for all the columns analysed in this research, were buckling curve "c" has been superimposed for comparison purposes. As can be seen, most of the values lie below the buckling curve "c" being therefore unsafe, except for columns with high relative slenderness values (generally corresponding to specimens with room temperature slenderness over 1.5) and columns with a very small slenderness. It becomes clear from this graph that columns with intermediate slenderness deviate from the theoretical buckling curve at elevated temperatures and therefore need another consideration. This result suggests that a set of flexural stiffness reduction coefficients $\varphi_{i, \theta}$ must be developed for CFT columns in combination with a possible revision of the buckling curve which provides a better fit to the data, matter that will be studied in depth throughout this paper. 
Another important aspect can be observed from Fig. 3. In the range of low slenderness, for each diameter of the columns analysed, the buckling coefficient $\chi$ of the columns with the maximum wall thickness of the tube (reduced $D / t$ values) appeared to be smaller than the $\chi$ values of the columns with the minimum wall thickness and thus having a higher $D / t$; e.g. the points for columns of $406.4 \times 16 \mathrm{~mm}$ section lie below the points corresponding to columns of $406.4 \times 8 \mathrm{~mm}$ section). This result was more evident in stocky columns $(\bar{\lambda} \leq 0.5)$, while for slender columns the difference was not so clear. It is worth noting that this phenomenon was found when comparing buckling coefficients (where the buckling load is referred to the crosssectional plastic resistance) and not with the absolute value of the buckling load, which resulted generally in higher values for the columns with a higher steel tube wall thickness.

The explanation of this may reside in the fact that for a given section size, lower thicknesses of the steel tube wall allow more quantity of concrete to fill the column and thus contributing to delay its heating and as a consequence being able to sustain a higher load. This behaviour holds true for this particular range of columns, where the fire response is highly influenced by the amount of concrete filling. However, the more slender columns show the inverse response, since their failure is initiated by the local buckling of the steel tube at an early stage when it is still sustaining the load without the contribution of the concrete core. The slenderness of the unfilled steel tube (and thus its thickness) is therefore a relevant factor in this case, whereas the amount of concrete filling does not play an important role here. This phenomenon was already addressed in previous numerical investigations carried out by the authors [23] and other groups [8], and has also been observed in real fire tests [30]. 


\section{STUDY AND DISCUSSION OF EUROCODE 4 PART 1.2}

On the basis of the results of the parametric studies presented above, a comparison is done in this section between the current calculation methods available in the Eurocode 4 Part 1.2 [15] for CFT columns. Four different approaches will be studied (see sections 2.1, 2.2, 2.3 from this paper): Clause 4.3.5.1 with flexural stiffness reduction coefficients equal to unity (EC4(1)), Clause 4.3.5.1 with the reduction coefficients proposed by Aribert et al. [20] (EC4(2)), Annex H (EC4(H)), and French National Annex [25] (EC4(NF)). For each method, the numerical temperature field obtained at the standard fire resistance classes (R30, R60, R90 and R120 minutes) was applied, and following the code provisions the buckling load was calculated.

Fig. 4 shows a comparison between the predictions and the numerical simulations in terms of normalised buckling load (divided by the theoretical cross-sectional plastic resistance). Fig. 5 plots the relative error of the predictions $\xi$ against the relative slenderness of the columns at room temperature, for each of the design approaches studied. The relative error was computed as follows:

$$
\xi=1-\frac{N_{f i, R d}^{P R E D}-N_{f i, R d}^{N U M}}{N_{f i, R d}^{N U M}}
$$

where $N_{f i, R d}{ }^{P R E D}$ is the predicted buckling resistance with the calculation method employed and $N_{f i, R d^{N U M}}$ is the numerical simulation result, which here is taken as the reference value. Therefore, values greater than 1 mean safe predictions, while values lower than 1 mean unsafe predictions.

As can be seen in Fig. 4a and Fig. 5a, EC4(1) yields unsafe results with a high dispersion of values for all the range of slenderness studied, except for $\bar{\lambda}=2$, when the predictions become safe and the dispersion is much lower. Therefore, to neglect the flexural stiffness reduction coefficients when applying Clause 4.3.5.1 of EC4 to CFT columns 
produces inadmissible errors. Nevertheless, when the French coefficients are used in combination with Clause 4.3.5.1, Fig. 4b and Fig. 5b (EC4(2)), safe results are obtained in all the range of slenderness studied (except for some cases with $\bar{\lambda} \leq 0.5$ ), but with high errors and an elevated dispersion of results. As the slenderness is increased, the predictions become safer but the errors produced by this method are higher. Annex H predictions $(\mathrm{EC} 4(\mathrm{H}))$ turn from safe at low slenderness $(\bar{\lambda}=0.3)$ to unsafe for intermediate slenderness $(\bar{\lambda}=0.5-1.5)$ and close to the reference value again at $\bar{\lambda}=2$, Fig. $4 \mathrm{c}$ and Fig. $5 \mathrm{c}$. This confirms the results from the CTICM group [20] [24], who found that the method in Annex $\mathrm{H}$ is unsafe for slenderness values over 0.4. Note that in these two figures, those cases which are out of the applicability limits of Annex $\mathrm{H}$ (buckling length $>4.5 \mathrm{~m}$ ) have been plotted with an empty mark. The magnitude of the error produced by Annex $\mathrm{H}$ is lower, but still leading to high errors, which in most of the cases are over a $25 \%$. Finally, EC4(NF) produces safe results for all the cases analysed, but with a high error which increases with the slenderness, Fig. 4d and Fig. 5d. Note that the number of points plotted in these two last figures is lower, since some column specimens are out of the applicability limits of the French method (only R30 and R60 are allowed for unreinforced columns).

The results obtained in this section confirm and extend the conclusions drawn by the authors in previous research [23].

\section{DEVELOPMENT OF A NEW SIMPLE CALCULATION MODEL FOR AXIALLY LOADED CONCRETE FILLED TUBULAR COLUMNS}

\subsection{Simplified cross-sectional temperature field}

In both Annex $\mathrm{H}$ and Clause 4.3.5.1 of EN 1994-1-2 [15] it is required that the designer obtains the cross-sectional temperature field in the composite cross-section after a given duration of fire exposure prior to applying the method to calculate the design axial buckling 
load. Nevertheless, no simplified method for the temperature evaluation is given in the code which helps the designer obtain easily this temperature field. In order to help practitioners in the future, a simple method for evaluating the temperature field within the cross-section of a CFT column of any dimensions is proposed here.

It would be desirable to obtain a uniform equivalent temperature for the whole concrete core $\left(\theta_{c, e q}\right)$ and another one for the steel tube $\left(\theta_{a, e q}\right)$ so as to obtain the same fire resistance of the column as by using the real non-uniform temperature distribution. This approach is already used in Annex G of EN 1994-1-2 [15] for composite columns with partially encased steel sections. The benefit of this approach is that the designer can evaluate the fire resistance of the column by using a single strength and stiffness value for each component of the composite cross-section corresponding to its temperature. A calculation procedure was proposed by Leskela [19], whose recommendations are followed hereafter.

\section{Calculation of the equivalent temperature for the concrete core}

The concrete cross-section is subdivided in a number of $n$ layers, being $A_{c, \theta, i}$ the area of a particular layer $i$ at the temperature $\theta$ and $I_{c, \theta, i}$ the second moment of area of that same layer. The equivalent temperature representing the whole concrete core can be found through two different approaches:

a) Plastic resistance approach

The plastic resistance to axial compression of the concrete core in the fire situation is equal to:

$$
N_{f i, p l, R d, c}=\sum_{i=1}^{n}\left(A_{c, \theta, i} f_{c, \theta, i}\right)=\sum_{i=1}^{n}\left(A_{c, \theta, i} k_{c, \theta, i} f_{c}\right)=f_{c} \sum_{i=1}^{n}\left(A_{c, \theta, i} k_{c, \theta, i}\right)
$$

A single equivalent temperature is needed, which produces the same plastic resistance through its corresponding reduction factor when applied to the whole concrete core: 
$N_{f i, p l, R d, c}=f_{c} \sum_{i=1}^{n}\left(A_{c, \theta, i} k_{c, \theta, i}\right)=k_{c, \theta}\left(\theta_{c, e q 1}\right) f_{c} A_{c} \rightarrow k_{c, \theta}\left(\theta_{c, e q 1}\right)=\frac{\sum_{i=1}^{n}\left(A_{c, \theta, i} k_{c, \theta, i}\right)}{A_{c}}$

Once this reduction coefficient is calculated, the equivalent temperature $\theta_{c, e q 1}$ representing the whole concrete core can be found through Table 3.3 in EN 1994-1-2 [15] by using linear interpolation.

b) Flexural stiffness approach

The flexural stiffness of the concrete core in the fire situation is equal to:

$(E I)_{f i, c}=\sum_{i=1}^{n}\left(E_{c, \mathrm{sec}, \theta, i} I_{c, \theta, i}\right)=\sum_{i=1}^{n}\left(\frac{f_{c, \theta, i}}{\varepsilon_{c u, \theta, i}} I_{c, \theta, i}\right)=\frac{f_{c}}{\varepsilon_{c u}} \sum_{i=1}^{n}\left(\frac{k_{c, \theta, i}}{\frac{\varepsilon_{c u, \theta, i}}{\varepsilon_{c u}}} I_{c, \theta, i}\right)=E_{c, \sec } \sum_{i=1}^{n}\left(k_{E c, \theta, i} I_{c, \theta, i}\right)$

with $k_{E c, \theta, i}=k_{c, \theta, i} \varepsilon_{c u} / \varepsilon_{c u, \theta, i}$.

It is required to obtain an equivalent temperature which produces the same flexural stiffness through its corresponding reduction factor when applied to the whole concrete core:

$(E I)_{f i, c}=E_{c, \sec } \sum_{i=1}^{n}\left(k_{E c, \theta, i} I_{c, \theta, i}\right)=k_{E c, \theta}\left(\theta_{c, e q 2}\right) E_{c, \sec } I_{c} \rightarrow k_{E c, \theta}\left(\theta_{c, e q 2}\right)=\frac{\sum_{i=1}^{n}\left(k_{E c, \theta, i} I_{c, \theta, i}\right)}{I_{c}}$

Once this coefficient is calculated, the equivalent temperature $\theta_{c, e q 2}$ representing the whole concrete core can be found through Table 3.3 in EN 1994-1-2 [15] by using linear interpolation and considering $k_{E c, \theta}=k_{c, \theta} \varepsilon_{c u} / \varepsilon_{c u, \theta}$.

Conservatively, the equivalent temperature of the concrete core will be defined as the maximum of the temperatures obtained through the two approaches described above:

$$
\theta_{c, e q}=\max \left\{\theta_{c, e q 1}, \theta_{c, e q 2}\right\}
$$


The previous procedure was applied to the different cross-sections used in the parametric studies, for which the temperature field had been calculated by means of the numerical model. The diameters studied covered a wide range of section factor values (from 7.87 to 28.63$)$. In this research, the number of layers $n$ within the concrete cross-section was chosen in such a way that the width of the individual layers did not exceed $20 \mathrm{~mm}$. Therefore, as the diameter of the column increases, a higher number of layers is required. The equivalent temperature of the concrete core was obtained for four different standard fire resistance classes: R30, R60, R90 and R120. The evolution of the equivalent temperature of the concrete core with the section factor of the columns is plotted in Fig. 6. As expected, as the fire exposure time increases, the equivalent temperatures also increase. The equivalent temperatures are also affected by the section factor of the columns, reaching higher values for those columns with higher section factors (i.e. small diameters), which expose a relatively high surface to the fire for the same volume and thus heat up faster. For each section factor and fire period, two points are plotted, corresponding to the two different steel tube wall thicknesses analysed. It can be observed that no significant influence is obtained with a change in the steel tube wall thickness, and therefore this parameter will not be taken into account in the development of the equivalent temperature proposal.

For each of the standard fire resistance classes studied, a regression curve was fitted to the data, as can be seen in Fig. 6. With the aid of the regression equations, a selection chart was built up (Table 2) to facilitate designers obtain the equivalent temperature of the concrete core for a particular fire period directly from the value of the section factor of the column. For intermediate values of the section factor, linear interpolation can be used. Note that the section factor of a circular CFT column is calculated as $4 / D\left(\mathrm{~m}^{-1}\right)$. 
It is worth noting that the temperatures close to $1000^{\circ} \mathrm{C}$ which are obtained at $\mathrm{R} 120$ for the smaller diameters (high section factors) are only indicative, nevertheless they cannot be reached in practice, since they would correspond to columns loaded at a very low level.

A unique equation for the equivalent temperature of concrete valid for any fire resistance period was also developed by using a multiple nonlinear regression analysis, which includes the effect of $A_{m} / V$ and $R$ :

$\theta_{c, e q}=-186.44+5.764 R-0.026 R^{2}+22.577 A_{m} / V-0.32\left(A_{m} / V\right)^{2}+0.14 R \cdot A_{m} / V$

This equation can be used as an alternative to the selection chart.

\section{Calculation of the equivalent temperature for the steel tube}

In the case of the steel tube, the equivalent temperature corresponding to each of the columns for a standard fire time was obtained directly from the numerical analysis without the need of employing the procedure described above, since its temperature remains almost uniform through the wall thickness for each fire period.

The equivalent temperatures for the steel tube $\left(\theta_{a, e q}\right)$ have been included in Table 2 , for the different values of the section factor and the four standard fire resistance classes. For intermediate values of the section factor, linear interpolation can be used.

An alternative equation for the equivalent temperature of the steel section was developed by using a multiple nonlinear regression analysis, including the effect of $A_{m} / V$ and $R$ and therefore valid for any fire resistance period:

$\theta_{a, e q}=342.1+10.77 R-0.044 R^{2}+3.922 A_{m} / V-0.025 R \cdot A_{m} / V$

The temperature obtained through this equation can be used instead of the one obtained by means of the selection chart. 


\subsection{Flexural stiffness reduction coefficients}

The applicability of the general principles in Clause 4.3.5.1 of EC4 [15] has been studied in Section 4 by comparing the predictions of the method (with some assumptions regarding the reduction coefficients) to the results obtained by means of the numerical model. It has been revealed that the predicted buckling loads result in most cases unsafe when the reduction coefficients are assumed to be equal to unity, which confirms the findings of previous work [22] [23].

Thus, a set of flexural stiffness reduction coefficients different to unity should be applied. Also the buckling curve should be revised as suggested by other authors [17] [19] [20].

Through the results of the parametric studies presented in this paper, the values of these coefficients will be derived for the standard fire exposure times. The procedure employed to calculate the theoretical values of the coefficients is described next.

In what follows, the value of the concrete flexural stiffness reduction coefficient will be taken as $\varphi_{c, \theta}=0.8$ and the initial tangent stiffness will be used (calculated as $3 / 2$ times the secant modulus), as the researchers from CTICM [20] [24] proposed. In fact, the value of 0.8 is already being used in Annex G of EN 1994-1-2 for composite columns with partially encased steel sections. If the secant modulus of concrete is used, as it is specified in Clause 4.3.5.1 of EN 1994-1-2, the coefficient $\varphi_{c, \theta}$ should be taken as 1.2. This value accounts for the effect of the differential thermal stresses produced by the unequal temperature field along the width of the concrete cross-section, which other authors have reported in their research [16] [20] [40]. The reduction coefficient for the steel tube will be then derived from the numerical data and assuming the concrete contribution to be known. 
By means of the numerical simulations results, the buckling coefficient corresponding to each column is obtained as the computed buckling resistance divided by the theoretical cross-sectional plastic resistance at the time of failure.

$$
\chi^{N U M}=\frac{N_{f i, R d}^{N U M}}{N_{f i, p l, R d}}
$$

Once the buckling coefficient $\chi^{N U M}$ is calculated, the relative slenderness of the column at elevated temperature $\bar{\lambda}_{\theta}{ }^{N U M}$ can be obtained from the corresponding buckling curve (here, buckling curve "a" was used, since it showed to produce a better fit to the data). With this value, the elastic critical load in the fire situation can be derived from equation (6):

$$
N_{f i, c r}{ }^{N U M}=\frac{N_{f i, p l, R}}{\left(\bar{\lambda}_{\theta}^{N U M}\right)^{2}}
$$

where $N_{f i, p l, R}$ can be calculated with equation (3).

Buckling curve "a" was not chosen for the elevated temperature design by chance; in fact this curve was selected as an intend of using the same buckling curve as in the main part of Eurocode 4 for room temperature design (EN 1994-1-1 [39]), which employs buckling curve "a" for CFT columns with a percentage of reinforcement under a 3\%. As later on will be demonstrated, this buckling curve provided a better fit to the analysis data. Wang [17] also defended the use of column buckling curve "a" instead of "c" on his work, proving that more accurate results were obtained when using the elevated temperature material models in the main text of Eurocode 4 Part 1.2 [15].

Using now the definition of the Euler buckling load (equation 5), the numerical value of the effective flexural stiffness of the column in the fire situation can be determined:

$$
(E I)_{f i, e f f}^{N U M}=\frac{N_{f i, c r}{ }^{N U M} \cdot \ell_{\theta}^{2}}{\pi^{2}}=\sum_{j}\left(\varphi_{a, \theta} E_{a, \theta} I_{a, \theta}\right)+\sum_{m}\left(\varphi_{c, \theta} E_{c, \theta} I_{c, \theta}\right)
$$

which is set equal with the summation of the contribution of the different layers. 
Through this value and being known $E_{a, \theta} I_{a, \theta}$ for the steel tube layers and $E_{c, \theta} I_{c, \theta}$ for the different layers within the concrete core, the reduction coefficient for steel can be obtained, provided that a fixed value is assigned to the reduction coefficient of concrete, which here was equalled to 0.8 , and considering only one layer in the steel tube wall.

$\varphi_{a, \theta}=\frac{(E I)_{f i, e f f}^{N U M}-\sum_{m}\left(\varphi_{c, \theta} E_{c, \theta} I_{c, \theta}\right)}{E_{a, \theta} I_{a, \theta}}$

Following this procedure, the numerical value of the steel flexural stiffness reduction coefficient was obtained for each of the columns analysed in the parametric study. Through a statistical study of the values obtained, it became clear that this coefficient is a complex function of the different variables that interact in the problem, such as the member

slenderness (trough $\bar{\lambda}$ or $\left.\ell_{\theta} / D\right)$, cross-sectional slenderness $(D / t)$ and section factor $\left(A_{m} / V\right)$, and cannot be readily transformed into a unique value of the coefficient or a simple analytical expression. Therefore, an equation depending on the different parameters or alternatively a set of tabulated data must be developed.

A correlation analysis was first performed in order to investigate the strength of the dependency between $\varphi_{a, \theta}$ and the independent variables. The results showed that there was a high correlation with the relative slenderness (an therefore with $\ell_{\theta} / D$ ) and a moderated correlation with $D / t$ and $A / V$. Nevertheless, no correlation was found with the standard fire exposure time, and therefore this variable was not used in the development of the design equation.

\section{Design equation}

On a first instance, the shape of the relationship of $\varphi_{a, \theta}$ with each of the independent variables was studied by means of univariant analysis, and afterwards a more complex 
equation which used the three independent variables was built up, in the form of a product of three factors:

$\varphi_{a, \theta}=\varphi_{a, \theta 1}(D / t) \times \varphi_{a, \theta 2}\left(A_{m} / V\right) \times \varphi_{a, \theta 3}\left(\ell_{\theta} / D\right)$

where the first term represents the influence of the cross-sectional slenderness, the second term the effect of the section factor (which determines the temperature field pattern within the cross-section) and the third term measures the influence of the member slenderness.

Based on the results of the previous statistical analysis, the following shape of the functions was proposed:

$\varphi_{a, \theta}=\varphi_{a, \theta 1}(D / t) \times\left(a_{0}+a_{1} \cdot\left(A_{m} / V\right)^{a_{2}}\right) \times\left(b_{0}+b_{1} \cdot\left(\ell_{\theta} / D\right)^{b_{2}}\right)$

The first factor $\varphi_{a, \theta l}$ was found to have only a moderate effect for the stocky columns $\left(\ell_{\theta} / D \leq 12\right)$, whereas for slender columns it did not show an important influence, therefore it was designed as a correction factor which must only be applied to columns with low slenderness.

A multiple nonlinear regression analysis of the simulated data was conducted in order to obtain the coefficients associated with the proposed equation. The corresponding regression equation results:

$\varphi_{a, \theta}=\varphi_{a, \theta 1}(D / t) \times\left(2.747-1.48 \cdot\left(A_{m} / V\right)^{0.08}\right) \times\left(0.0813+0.0133 \cdot\left(\ell_{\theta} / D\right)^{1.097}\right) \leq 1$

In this equation, the reduction coefficient $\varphi_{a, \theta}$ is a product of two partial reduction coefficients lower than unity, $\varphi_{a, \theta_{2}}$ and $\varphi_{a, \theta 3}$, which are corrected by the factor $\varphi_{a, \theta_{1}}$ as a function of $D / t$ only for stocky columns $\left(\ell_{\theta} / D \leq 12\right)$, using the values tabulated in Table 3 . For $\ell_{\theta} / D>12$, the factor $\varphi_{a, \theta l}$ is equal to unity. 
For $\ell_{\theta} / D \geq 46$, which corresponds to columns with relative slenderness at room temperature $\bar{\lambda}$ around 2, the total factor $\varphi_{a, \theta}$ can be taken as equal to unity, which means that the reduction coefficient for the steel tube can be neglected.

Once the reduction coefficients have been calculated through the proposed equation, the general principles in Clause 4.3.5.1 of EN 1994-1-2 [15] can be followed, with the only particularity of using buckling curve "a" instead of "c".

The design equation presented here was applied to all the data available from the parametric studies in order to obtain the predicted values of the buckling resistance, and for each case specimen the error was measured with the expression in (9), obtaining an average value of the error equal to 1.09 (safe) and a standard deviation of 0.11 .

\section{Tabulated data}

A more simplistic proposal was also developed, in the form of a selection table where the values of the reduction coefficient $\varphi_{a, \theta}$ can be obtained as a function of the section factor $A_{m} / V$ and the elevated temperature slenderness, measured as $\ell_{\theta} / D$. The values of the reduction coefficient for the steel tube for different combinations of the two parameters can be found in Table 4. For intermediate values of $\ell_{\theta} / D$, linear interpolation may be used. To account for the effect of the cross-sectional slenderness of the steel tube, the resulting coefficient must be corrected by the factor $\varphi_{a, \theta l}$ as a function of $D / t$ if $\ell_{\theta} / D \leq 12$, using the values tabulated in Table 3. Again, for higher values of $\ell_{\theta} / D$, no correction is needed.

The reduction coefficient of concrete $\varphi_{c, \theta}$ must be taken as a constant value equal to 0.8 and used with the tangent modulus. With these values, the general principles in Clause 4.3.5.1 of EN 1994-1-2 [15] can be followed, using buckling curve "a" as mentioned before. With the tabulated method, a mean error equal to 1.04 with a standard deviation of 0.11 was obtained. 
It is worth noting that the resulting coefficients are much lower for steel than for concrete, which means that the flexural stiffness of the steel tube is more highly affected than the concrete core in the fire situation as compared to their theoretical values. The explanation to the low values of the steel reduction coefficient is that it incorporates the effect of the overload of the steel tube during the early stages of the fire exposure. To the authors' point of view, more than representing the possible effect of the thermal stresses, in the case of steel, this coefficient acts as a reduction factor to account for this overload, which is generally not taken into account and reduces significantly the fire resistance of the column. How this overload affects the fire performance of the column is a complex combination of different factors such as the member slenderness, the cross-sectional dimensions and the fire exposure time, which are included in the proposed equations. Nevertheless, in the case of concrete, the reduction coefficient represents the effect of the differential thermal stresses developed as a result of the non-uniform temperature distribution within the concrete core, which other authors have explained before [16] [20] [40].

Fig. 7a shows a comparison between the predictions and the numerical simulations in terms of normalised buckling load (divided by the theoretical plastic resistance) and Fig. $7 \mathrm{~b}$ plots the errors of the predictions against the relative slenderness of the columns at room temperature, for the proposed method using the design equation (23) and buckling curve "a". Fig. 8 presents the evolution of the buckling coefficient with the relative slenderness at elevated temperature. As can be seen, there is a good agreement between the predicted and reference values, with a maximum relative error of a $25 \%$ (only exceeded in a few number of cases which lay on the safe side) and a reasonably uniform distribution of the prediction errors for all the range of relative slenderness studied. Using the proposed coefficients, obtained by means of the design equation (23), or alternatively through the tables, the data follow closely the reference buckling curve "a", as can be seen in Fig. 8, with an excellent 
agreement for the higher slenderness and a moderated dispersion for intermediate slenderness but still following the shape of the normalised buckling curve and remaining on the safe side for short columns.

The frequency histogram plotted in Fig. 9 shows that the prediction errors follow the shape of a normal distribution, with the mean value located on the safe side (where the most repeated values can be found) and a narrow dispersion.

The proposed calculation method can only be applied in the following conditions:

- Buckling length in the fire situation: $\ell_{\theta} / D<50$ and $\ell_{\theta}<10 \mathrm{~m} *$

- Diameter of the cross-section: $139.7 \mathrm{~mm} \leq D \leq 508 \mathrm{~mm}$

- Normal strength concrete: C20/25 - C40/50

- Standard fire resistance: $R \leq 120 \mathrm{~min}$

* Note that a buckling length equal to 10 meters in the fire situation corresponds to a column with a real length equal to 20 meters placed on an intermediate storey, according to Clause 4.3.5.1(10) in EN 1994-1-2 [15].

\section{COMPARISON OF THE PROPOSED METHOD WITH EXPERIMENTS}

The proposed method is compared in this section with real fire tests carried out recently by the authors in the laboratories of AIDICO (Valencia, Spain) [32] and also against the tests available in the literature from the experimental program conducted at the Institute for Research in Construction, National Research Council of Canada (NRCC) [30].

From both sources, only those column specimens within the range of application of the method were selected, i.e. columns of circular cross-section, filled with plain (unreinforced) normal strength concrete (C20-C40) and centrally loaded. Fig. 10 compares the results of all the tests against the predictions of the method, in terms of the failure load. For the Canadian tests, the equivalent temperatures for steel and concrete were obtained for the failure time reported at the tests as described in Section 5.1 and afterwards the method in Section 5.2 was 
applied using the calculated temperatures. It can be seen in Fig. 10 that the accuracy of the method was reasonable given the uncertainties that one can find when using data from external tests, and in general the predictions were conservative.

For comparing with the own tests by the authors, two options were considered: using the calculated equivalent temperatures for steel and concrete and using the real temperatures measured at the tests. As can be observed in Fig. 10, a better approximation was obviously obtained under the second option, since the real temperatures were employed; in any case using the simplified equivalent temperatures produced safe results for all the specimens compared, what confirms that the method described in Section 5.1 for obtaining the simplified cross-sectional temperature field can be safely applied in combination with the general principles in Clause 4.3.5.1 of EN 1994-1-2 [15], with the flexural stiffness reduction coefficients calculated as described in Section 5.2 and the use of buckling curve "a".

Fig. 11 compares the results of the proposed method with the values of the predictions obtained by means of other three methods which are being used worldwide and which were previously described in Section 2: the design equation proposed by Kodur [6] (used in North America), the strength index formulation proposed by Han [4] (used in China) and the method from ANUHT 2004 [13] (used in Japan). As can be seen, the proposed method results generally safer than the rest of the methods. A wide dispersion of results is found under all the methods when comparing with real fire tests, being higher for the formulations from Han and Kodur, while the Japanese method seems to provide a narrower dispersion and more accurate predictions. Compared to the rest of the methods, it can be concluded that the proposed method provides a reasonable accuracy in the predictions and tends to be on the safe side. 


\section{DESIGN EXAMPLE}

The following design example illustrates the application of the proposed simple calculation model for obtaining the buckling resistance of an axially loaded CFT column for a specified standard fire period.

Consider that the designer wants to calculate the maximum axial load that a column placed on the top floor of a building can sustain during a period of 60 minutes of fire exposure. The column has the following characteristics:

- Column length: $L=3000 \mathrm{~mm}$

- Cross-sectional dimensions: $D \times t=159 \times 6 \mathrm{~mm}$

- Steel yield strength: $f_{y}=355 \mathrm{MPa}$

- Compressive strength of concrete: $f_{c}=30 \mathrm{MPa}$

First, the following parameters must be calculated:

- Section factor of the column: $A_{m} / V=4 / D=4 / 159 \times 1000=25.16 \mathrm{~m}^{-1}$

- Member slenderness in the fire situation: $\ell_{\theta} / D=(0.7 * \times 3000) / 159=13.21$

- Cross-sectional slenderness: $D / t=159 / 6=26.5$

*According to Clause 4.3.5.1(10) of EN 1994-1-2, for a column on the top floor of a building, the buckling length in the fire situation is calculated as 0.7 times the column length.

Note that the column in this example is being verified for axial loading conditions, which requires that the loads transferred to the column are balanced and do not introduce any bending effects at the top of the column.

On a first stage, the equivalent temperatures for the steel tube and concrete core must be obtained, by means of the proposed equations, or alternatively using the values in Table 2.

For the section factor of the column and the required standard fire period R60, the proposed equations (15) and (16) produce the following values, for the concrete core: 
$\theta_{c, e q}=-186.44+5.764 \times 60-0.026 \times 60^{2}+22.577 \times 25.16-0.32 \times 25.16^{2}+0.14 \times 60 \times 25.16=$ $=642.61^{\circ} \mathrm{C}$

and for the steel tube:

$\theta_{a, e q}=342.1+10.77 \times 60-0.044 \times 60^{2}+3.922 \times 25.16-0.025 \times 60 \times 25.16=890.84^{\circ} \mathrm{C}$

Alternatively, linear interpolation can be used in Table 2, obtaining $650.74{ }^{\circ} \mathrm{C}$ for the concrete core and $903.35{ }^{\circ} \mathrm{C}$ for the steel tube. The temperatures obtained through the equations will be used in this case.

Once the equivalent temperatures of steel and concrete are known for the specified fire period, the design values of the cross-sectional plastic resistance and effective flexural stiffness of the column can be calculated, following the rules in Clause 4.3.5.1 of EN 1994-1$2[15]$ and considering only one layer for the steel tube and concrete core:

$N_{f i, p l, R d}=A_{a} f_{y, \theta e q a}+A_{c} f_{c, \theta e q c}=$ $=2883.98 \mathrm{~mm}^{2} \times k_{y}(890.84) \times 355 \mathrm{MPa}+16971.67 \mathrm{~mm}^{2} \times k_{c}(642.61) \times 30 \mathrm{MPa}=$ $=2883.98 \times 0.0646 \times 355+16971.67 \times 0.3861 \times 30=262721.17 \mathrm{~N}=262.72 \mathrm{kN}$

The partial factors for the materials in the fire situation, $\gamma_{M, f i, i}$ have been taken as unity, as established in Clause 2.3 of EN 1994-1-2 [15].

Prior to obtaining the effective flexural stiffness, the values of the reduction coefficients $\varphi_{a, \theta}$ and $\varphi_{c, \theta}$ must be determined. The reduction coefficient of the concrete core is equal to 0.8 , and the reduction coefficient for the steel tube can be obtained from equation (23), resulting:

$\varphi_{a, \theta}=\varphi_{a, \theta 1} \times \varphi_{a, \theta 2} \times \varphi_{a, \theta 3}=1 \times\left(2.747-1.48 \cdot 25.16^{0.08}\right) \times\left(0.0813+0.0133 \cdot 13.21^{1.097}\right)=$ $=1 \times 0.83 \times 0.31=0.26$

Note that in this case the correction factor depending on the cross-sectional slenderness $\varphi_{a, \theta l}$ is not needed, since $\ell_{\theta} / D>12$, therefore it is equal to unity. 
The reduction coefficient for the steel tube can also be obtained from Table 4, where a value of 0.27 is found by using linear interpolation.

The effective flexural stiffness of the column after 60 minutes of fire exposure is:

$(E I)_{f i, e f f}=\varphi_{a, \theta} E_{a, \theta e q a} I_{a}+\varphi_{c, \theta} E_{c, \theta e q c} I_{c}=$

$=0.26 \times 210000 \mathrm{MPa} \times k_{E}(890.84) \times 8451869.91 \mathrm{~mm}^{4}+$

$+0.8 \times 3 / 2 \times k_{c}(642.61) \times 30 \mathrm{MPa} / \varepsilon_{c u}(642.61) \times 22921299.6 \mathrm{~mm}^{4}=$

$=0.26 \times 210000 \times 0.0696 \times 8451869.91+0.8 \times 3 / 2 \times 0.3861 \times 30 / 0.025 \times 22921299.6=$

$=44862333794.1 \mathrm{~N} \cdot \mathrm{mm}^{2}$

Now, the Euler buckling load in the fire situation can be calculated as:

$N_{f i, c r}=\pi^{2}(E I)_{f i, e f f} / \ell_{\theta}^{2}=\pi^{2} \times 44862333794.1 /(0.7 \times 3000)^{2}=100401.98 \mathrm{~N}=100.4 \mathrm{kN}$

and the relative slenderness of the column at elevated temperature therefore results:

$\bar{\lambda}_{\theta}=\sqrt{N_{f i, p l, R} / N_{f i, c r}}=\sqrt{262.72 / 100.4}=1.62$

This value of the relative slenderness is used to enter to the buckling curve "a", from where the reduction coefficient needed for determining the buckling load is obtained, which in this case is $\chi=0.32$.

Finally, the design value of the resistance of the column to axial compression after a period of 60 minutes results:

$N_{f i, R d}=\chi N_{f i, p l, R d}=0.32 \times 262.72 \mathrm{kN}=84.07 \mathrm{kN}$

\section{SUMMARY AND CONCLUSIONS}

This paper reviewed the current design guidelines which are available worldwide for calculating the fire resistance of CFT columns, specially focusing on the Eurocode 4 Part 1.2 approach. Given the inaccuracy and limitations of the Annex $\mathrm{H}$ on this code, a new proposal based on the general rules for composite columns in Clause 4.3.5.1 was developed. 
Parametric studies were carried out by means of a validated numerical model in order to investigate the main parameters affecting the fire behaviour of CFT columns, and through their results, design equations and tables were proposed for defining the appropriate values of the flexural stiffness reduction coefficients for the steel tube and concrete core.

A flexural stiffness reduction coefficient equal to 0.8 applied over the initial tangent modulus of concrete can be assumed to account for the thermal stresses, while for the steel tube more conservative coefficients are needed, in order to include the overload effect. The equations and tables proposed in this paper can be used in combination with buckling curve "a" to obtain a good estimation of the buckling resistance of CFT columns.

There was a good agreement between the proposed method predictions and the numerical simulations, with a uniform distribution of the error for all the range of relative slenderness studied, which clearly improves the accuracy of the currently available methods in Eurocode 4 Part 1.2.

Expressions and tables for obtaining the equivalent temperatures for the steel tube and concrete core were also developed, in order to facilitate the designer to apply the method without the need of using advanced heat transfer calculation tools.

It was demonstrated that the proposed method provides a good estimation of the buckling resistance of CFT columns at elevated temperatures as compared with real fire tests, producing safe predictions in the majority of the cases.

\section{ACKNOWLEDGEMENTS}

The authors would like to express their sincere gratitude to the Spanish "Ministerio de Ciencia e Innovación” for the help provided through the Project BIA2009-9411 and to the European Union through the FEDER funds. 


\section{REFERENCES}

[1] Zhao XL, Han LH, Lu H. Concrete-filled tubular members and connections. Spon Press; 2010.

[2] Rush D, Bisby L, Melandinos A, Lane B. Fire resistance design of unprotected concrete filled steel hollow sections: meta-analysis of available furnace test data. International Association of Fire Safety Science; 2011.

[3] DBJ13-51-2003: Technical specification for concrete-filled steel tubular structures (in Chinese). Fuzhou: The Construction Department of Fujian Province; 2003.

[4] Han LH, Zhao XL, Yang YF, Feng JB. Experimental study and calculation of the fire resistance of concrete-filled hollow steel columns. Journal of Structural Engineering, ASCE $2003 ; 129(3): 346-356$.

[5] Han LH, Yang YF, Xu L. An experimental study and calculation on the fire resistance of concrete-filled SHS columns. Journal of Constructional Steel Research 2003; 59(4):427452.

[6] Kodur VKR. Performance-based fire resistance design of concrete-filled steel columns. Journal of Constructional Steel Research 1999; 51:21-36.

[7] Kodur VKR. Guidelines for fire resistant design of concrete-filled steel HSS columns State-of-the-art and research needs. Steel Structures 2007; 7:173-182.

[8] Kodur VKR, MacKinnon DH. Design of concrete-filled hollow structural steel columns for fire endurance. Engineering Journal-AISC 2000; 37(1):13-24.

[9] Canadian Commission on Building and Fire Codes. NBCC, National Building Code of Canada. Ottawa, Canada: National Research Council of Canada (NRCC); 2005.

[10] ASCE, ASCE/SFPE 29-99: Standard Calculation Method for Structural Fire Protection. Reston, USA: American Society of Civil Engineers; 1999. 
[11] ACI, ACI 216.1M-07: Standard Method for Determining Fire Resistance of Concrete and Masonry Construction Assemblies. Detroit, USA: American Concrete Institute; 2007.

[12] Ruddy JL, Marlo JP, Ioannides SA, Alfawakhiri F. Fire Resistance of Structural Steel Framing. Steel Design Guide 19. Chicago, USA: American Institute of Steel Construction; 2003.

[13] Association of New Urban Housing Technology (ANUHT). Fire resistance design of non-insulated CFT columns - Guidelines, technical explanations and design examples (in Japanese); 2004

[14] Harada K. Actual state of the codes on fire design in Japan. Proceedings of the Workshop "Fire Design of Concrete Structures: What now? What next?". Milan, Italy, December 23, 2004. Brescia, Italy: Starrylink Editrice; 2004.

[15] CEN. EN 1994-1-2, Eurocode 4: Design of composite steel and concrete structures. Part 1-2: General rules - Structural fire design. Brussels, Belgium: Comité Européen de Normalisation; 2005.

[16] Wang YC, Orton AH. Fire resistant design of concrete filled tubular steel columns. The Structural Engineer 2008; 7:40-45.

[17] Wang YC. Some considerations in the design of unprotected concrete-filled steel tubular columns under fire conditions. Journal of Constructional Steel Research 1997; 44(3):203223.

[18] Wang YC. A simple method for calculating the fire resistance of concrete-filled CHS columns. Journal of Constructional Steel Research 2000; 54:365-386.

[19] Leskela MV. Inconsistencies in the fire design rules of composite columns to EN 1994-12. Steel Concrete Composite and Hybrid Structures, pp. 489-494. Leeds, England; 2009. 
[20] Aribert JM, Renaud C, Zhao B. Simplified fire design for composite hollow-section columns. Structures \& Buildings 2008; 161:325-336.

[21] Ribeiro JCL, Fakury RH, de Las Casas EB. Eurocode structural fire design and its application for composite circular hollow section columns. Journal of the Brazilian Society of Mechanical Science and Engineering 2008; 30(1):39-46.

[22] Espinos A, Romero ML, Hospitaler A. Advanced model for predicting the fire response of concrete filled tubular columns. Journal of Constructional Steel Research 2010; 66:1030-1046.

[23] Espinos A, Gardner L, Romero M, Hospitaler A. Fire behaviour of concrete filled elliptical steel columns. Thin-Walled Structures 2011; 49(2):239-255.

[24] Renaud C, Joyeux D, Kruppa J. Improvement and extension of the simple calculation method for fire resistance of unprotected concrete filled hollow columns. CIDECT Research Project 15Q-12/03. Saint-Rémy-lès-Chevreuse, France: Centre Technique Industriel de la Construction Métallique (CTICM); 2004.

[25] AFNOR. Calcul simplifié de la résistance au feu des profils creux remplis de béton exposés aux conditions d'incendie normalisé. Annexe PCRB, pp. 9-16, NF-EN 1994-12/NA. Paris, France: Association Française de Normalisation; 2007.

[26] Hicks SJ, Newman GM. Design guide for SHS concrete filled columns. Corus Tubes; 2002.

[27] Twilt L, Hass R, Klingsch W, Edwards M, Dutta D. Design guide for structural hollow section columns exposed to fire. Cologne, Germany: Comité International pour le Développement et l'Etude de la Construction Tubulaire (CIDECT); 1996.

[28] CEN. EN 1993-1-1, Eurocode 3: Design of steel structures. Part 1-1: General rules and rules for buildings. Brussels, Belgium: Comité Européen de Normalisation; 2005. 
[29] Lennon T, Moore DB, Wang YC, Bailey CG. Designers' guide to EN 1991-1-2, EN 1992-1-2, EN 1993-1-2 and EN 1994-1-2. Thomas Telford Limited; 2007.

[30] Lie TT, Chabot M. Experimental studies on the fire resistance of hollow steel columns filled with plain concrete. Internal report No. 611. Ottawa, Canada: Institute for Research in Construction, National Research Council of Canada (NRCC); 1992.

[31] ABAQUS. ABAQUS/Standard Version 6.6 User's Manual: Volumes I-III. Pawtucket, Rhode Island: Hibbit, Karlsson \& Sorenson, Inc.; 2005.

[32] Romero ML, Moliner V, Espinos A, Ibañez C, Hospitaler A. Fire behavior of axially loaded slender high strength concrete-filled tubular columns. Journal of Constructional Steel Research 2011; 67(12):1953-1965.

[33] ISO (International Standards Organization). ISO 834: Fire resistance tests, elements of building construction. Switzerland: International Standards Organisation; 1980.

[34] CEN. EN 1991-1-2, Eurocode 1: Actions on structures. Part 1-2: General actions Actions on structures exposed to fire. Brussels, Belgium: Comité Européen de Normalisation; 2002.

[35] Lie TT. Fire resistance of circular steel columns filled with bar-reinforced concrete. ASCE Journal of Structural Engineering 1994; 120(5):1489-1509.

[36] CEN. EN 1992-1-2, Eurocode 2: Design of concrete structures. Part 1-2: General rules Structural fire design. Brussels, Belgium: Comité Européen de Normalisation; 2004.

[37] Hong S, Varma AH. Analytical modeling of the standard fire behavior of loaded CFT columns. Journal of Constructional Steel Research 2009; 65:54-69.

[38] CEN. EN 1993-1-2, Eurocode 3: Design of steel structures. Part 1-2: General rules Structural fire design. Brussels, Belgium: Comité Européen de Normalisation; 2005. 
Espinos A, Romero ML, Hospitaler A. Simple calculation model for evaluating the fire resistance of unreinforced concrete filled tubular columns. Eng Struct. 2012;42:231-44. doi: 10.1016/j.engstruct.2012.04.022

[39] CEN. EN 1994-1-1, Eurocode 4: Design of composite steel and concrete structures. Part 1-1: General rules and rules for buildings. Brussels, Belgium: Comité Européen de Normalisation; 2004

[40] Bailey C. Effective lengths of concrete-filled steel square hollow sections in fire. Proceedings of the ICE - Structures and Buildings 2000; 140(2):169-178. 
Espinos A, Romero ML, Hospitaler A. Simple calculation model for evaluating the fire resistance of unreinforced concrete filled tubular columns. Eng Struct. 2012;42:231-44. doi: 10.1016/j.engstruct.2012.04.022

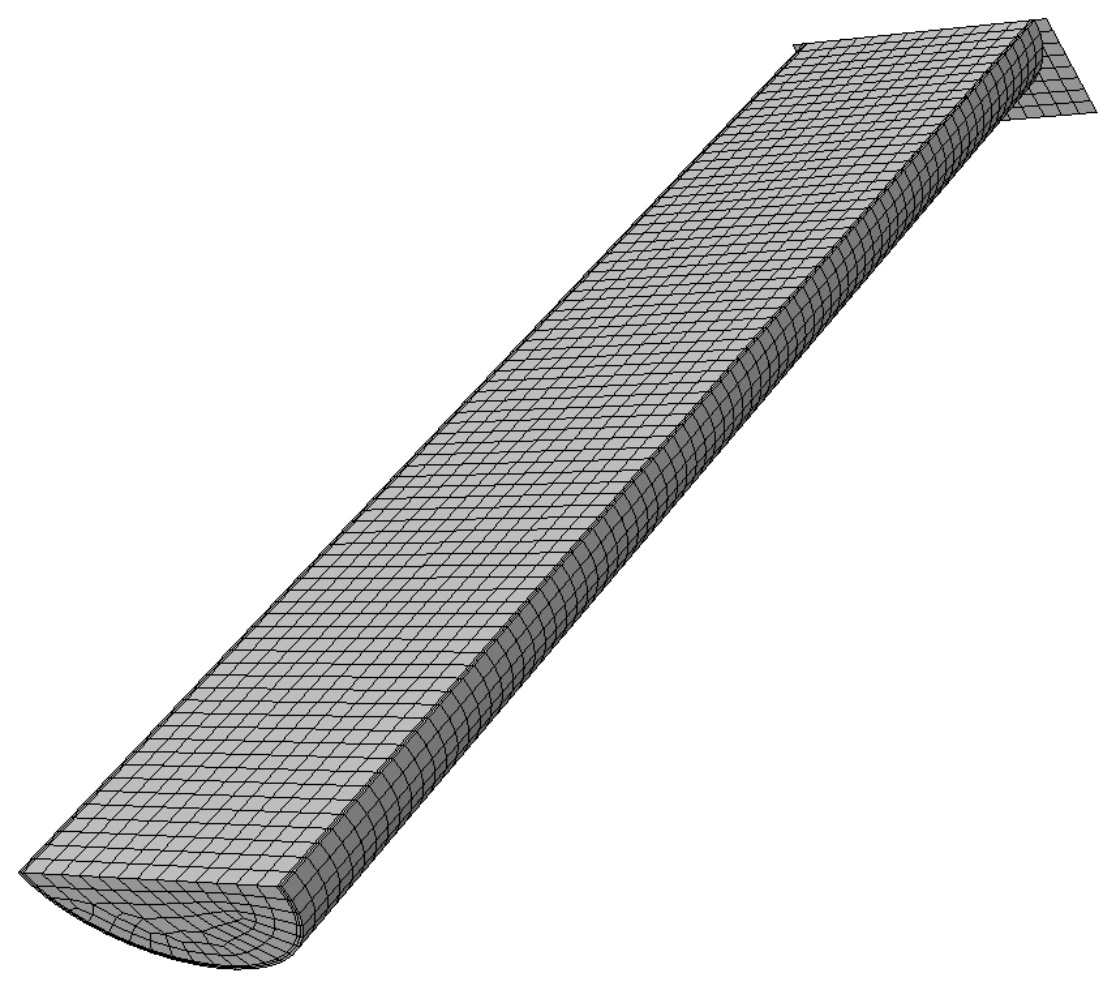

Fig. 1. Finite element mesh of the model for one of the columns analysed. 
Espinos A, Romero ML, Hospitaler A. Simple calculation model for evaluating the fire resistance of unreinforced concrete filled tubular columns. Eng Struct. 2012;42:231-44. doi: 10.1016/j.engstruct.2012.04.022

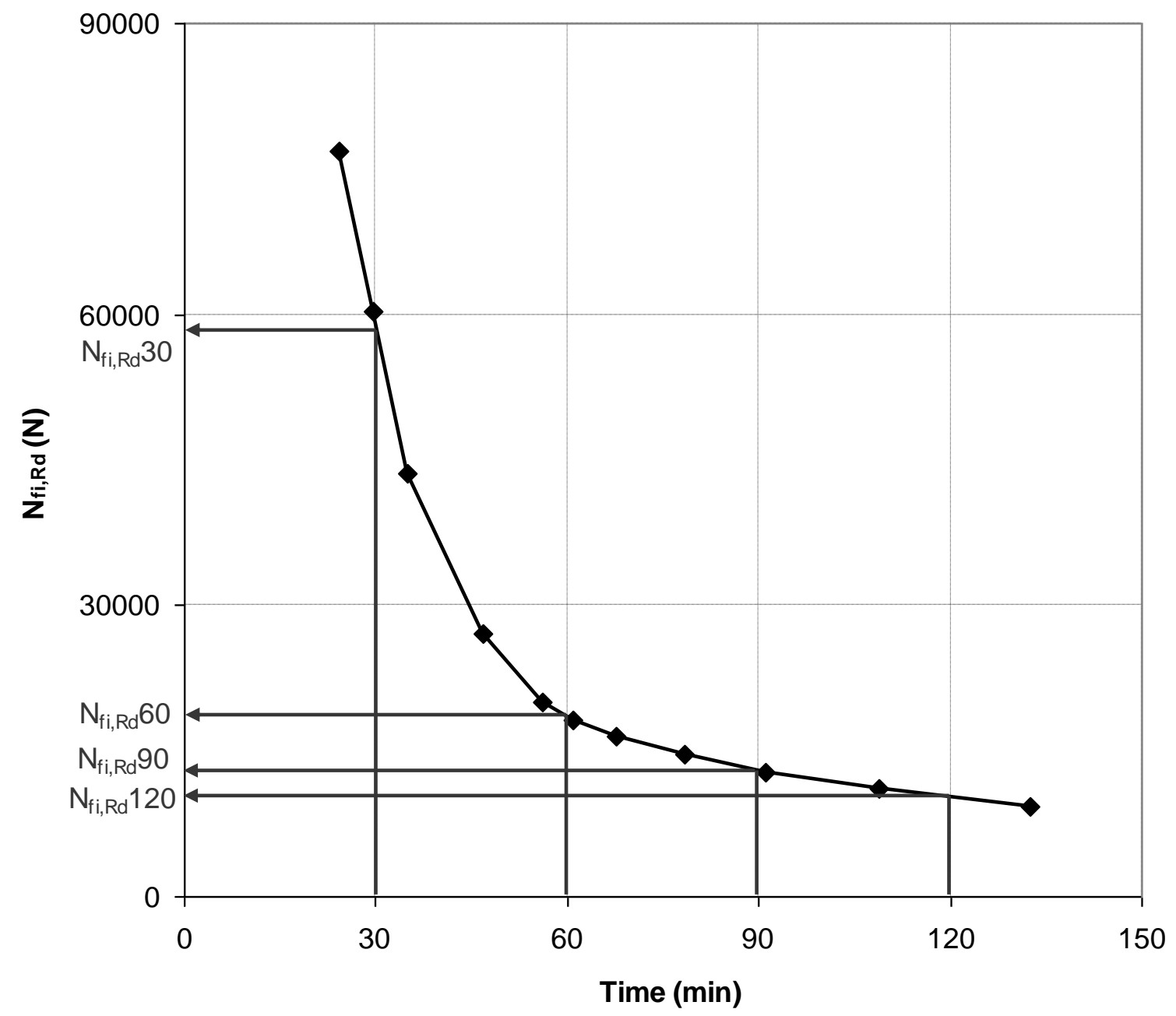

Fig. 2. Process for obtaining the buckling resistance of the columns at the different standard fire periods. 


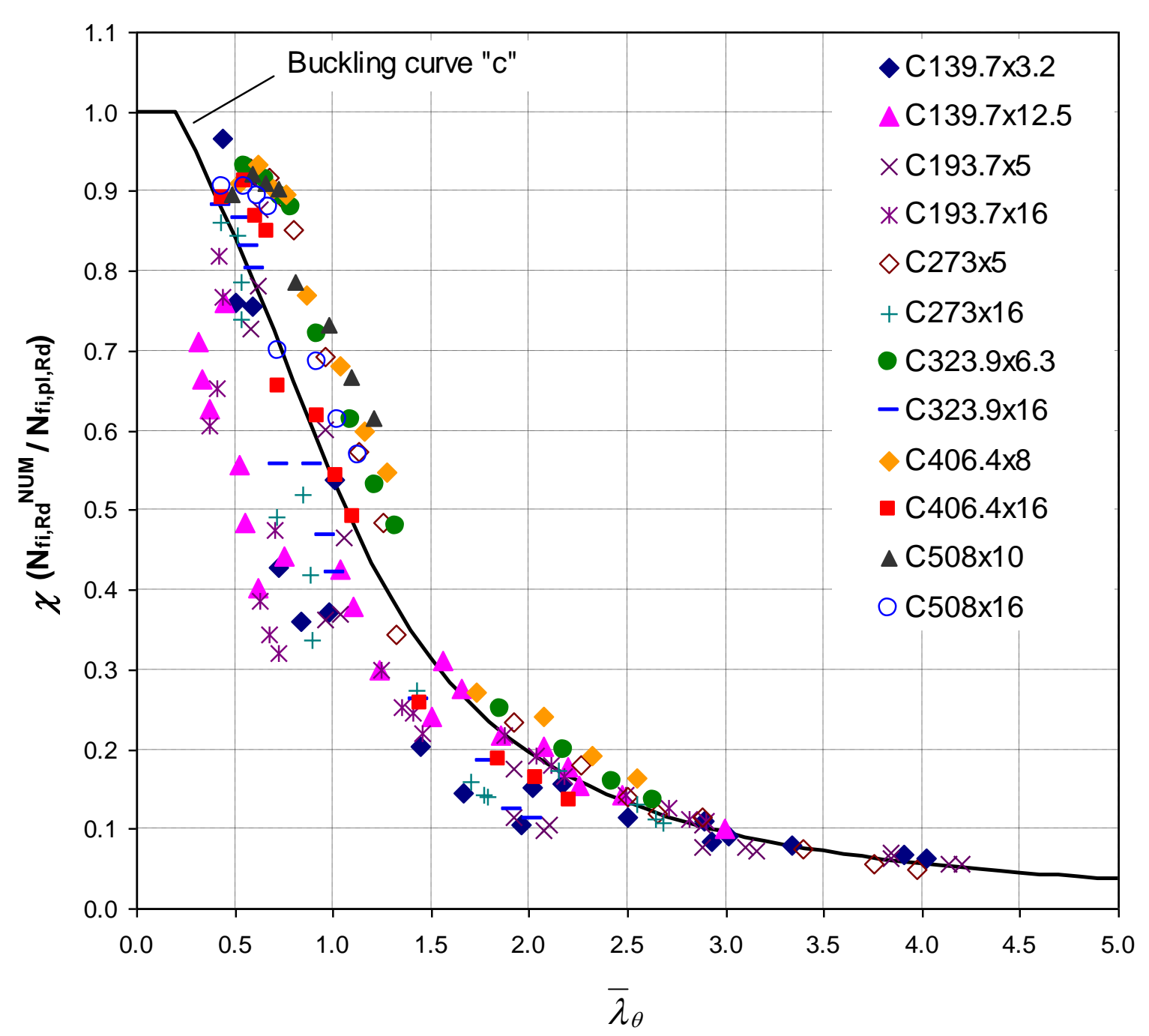

Fig. 3. Evolution of the buckling coefficient with the relative slenderness at elevated temperature (neglecting the flexural stiffness reduction coefficients). 

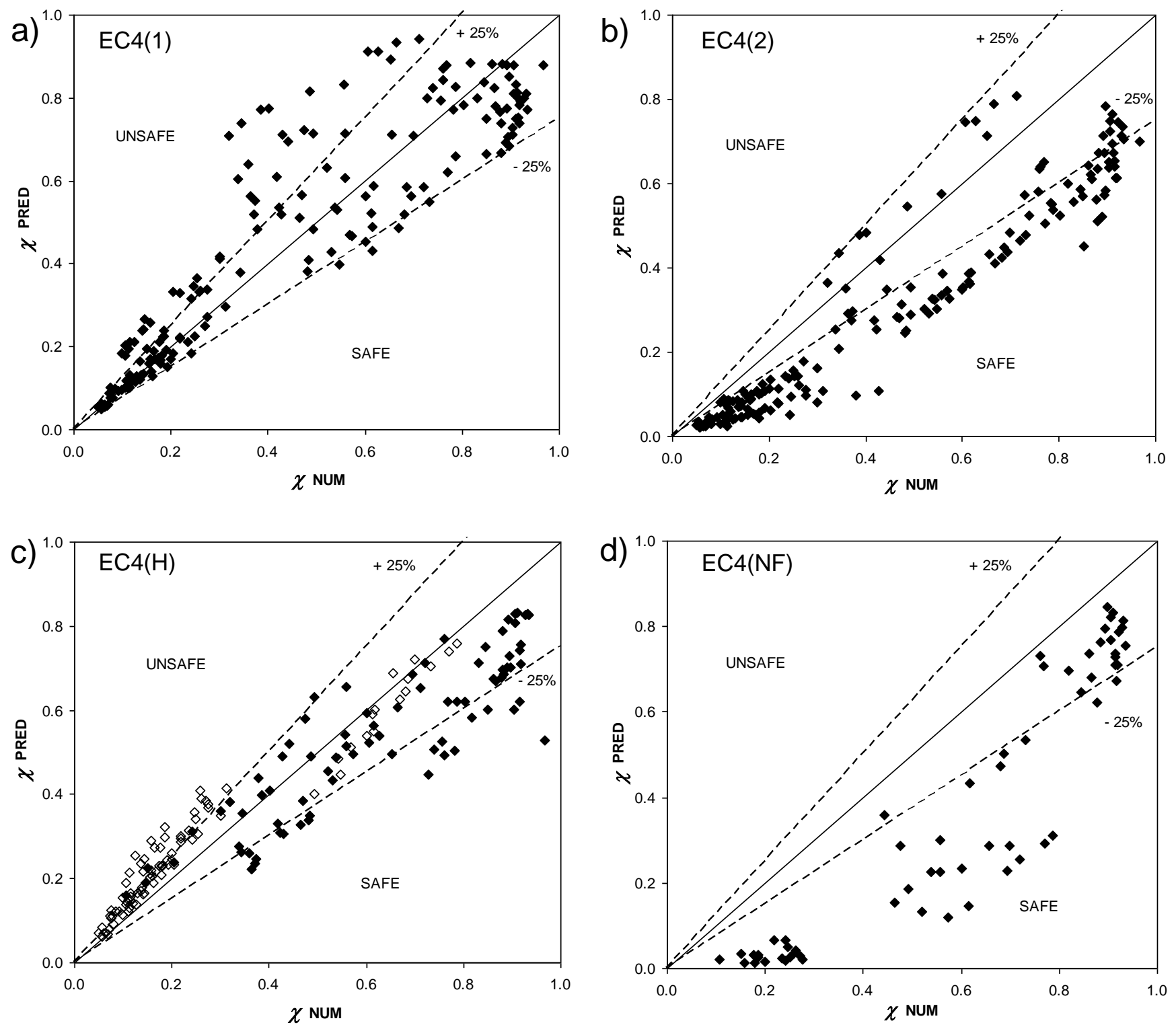

Fig. 4. Comparison between the different approaches studied in terms of the normalised buckling resistance: a) EC4(1), b) EC4(2), c) EC4(H), d) EC4(NF). 
a)

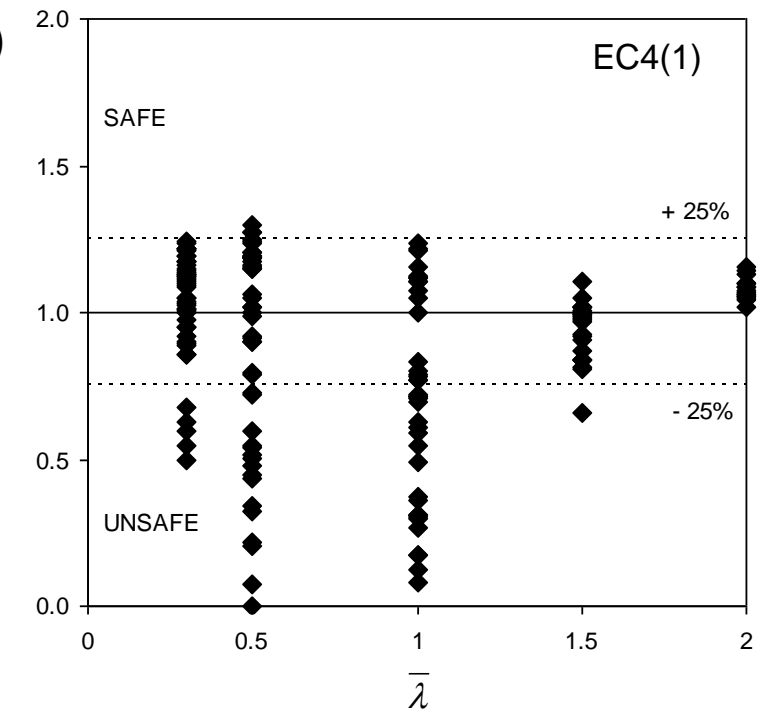

c)

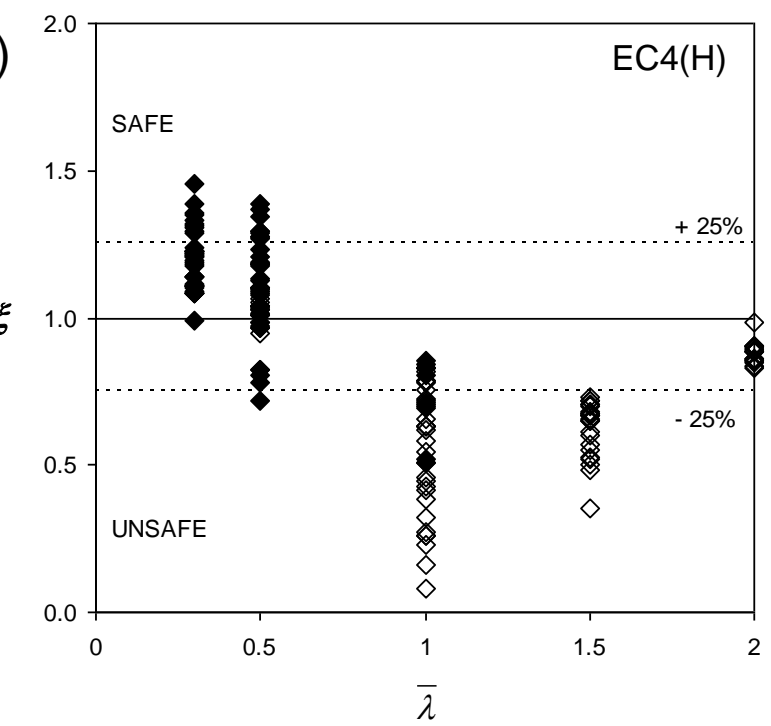

b)

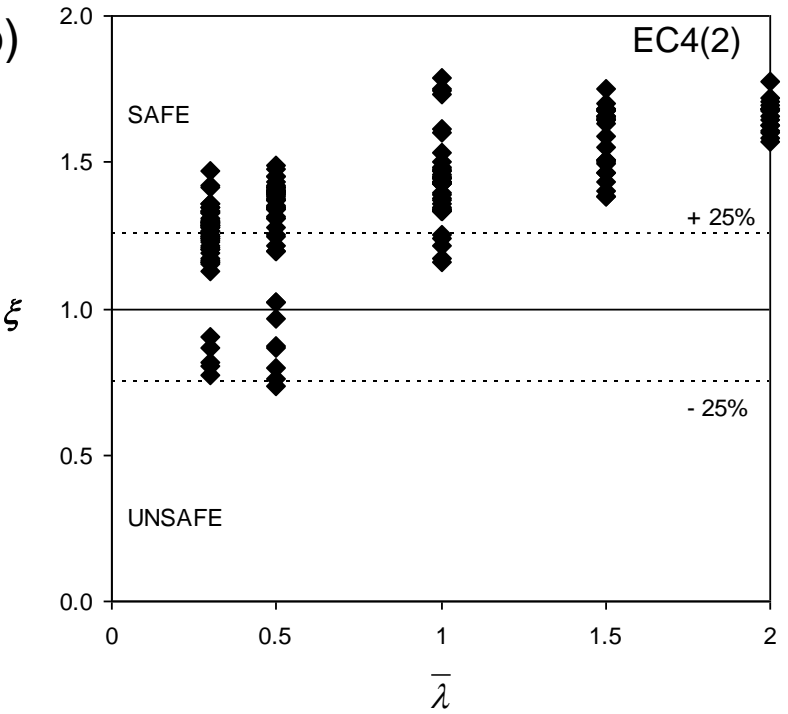

d)

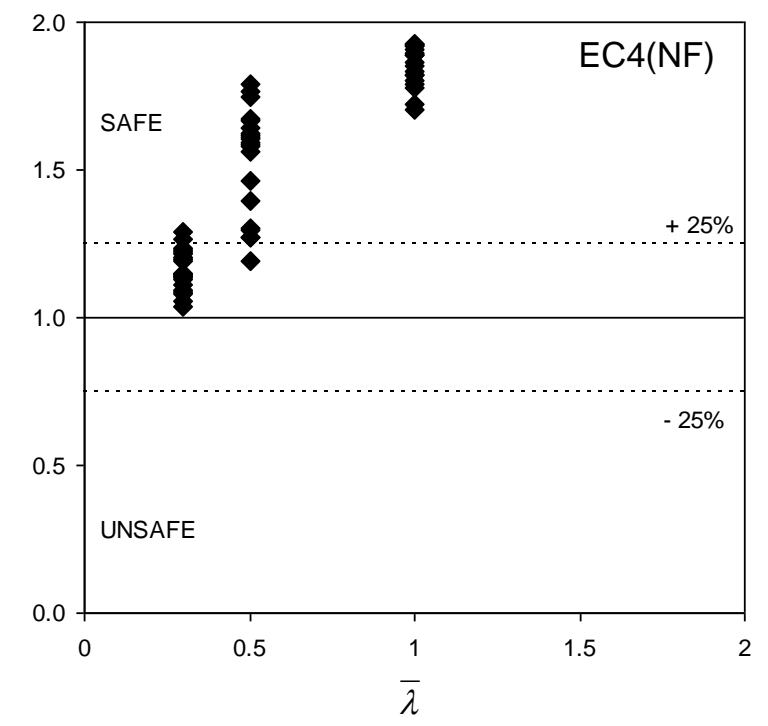

Fig. 5. Evolution of the prediction errors with the relative slenderness of the columns, for the different approaches studied: a) EC4(1), b) EC4(2), c) EC4(H), d) EC4(NF). 
Espinos A, Romero ML, Hospitaler A. Simple calculation model for evaluating the fire resistance of unreinforced concrete filled tubular columns. Eng Struct. 2012;42:231-44. doi: 10.1016/j.engstruct.2012.04.022

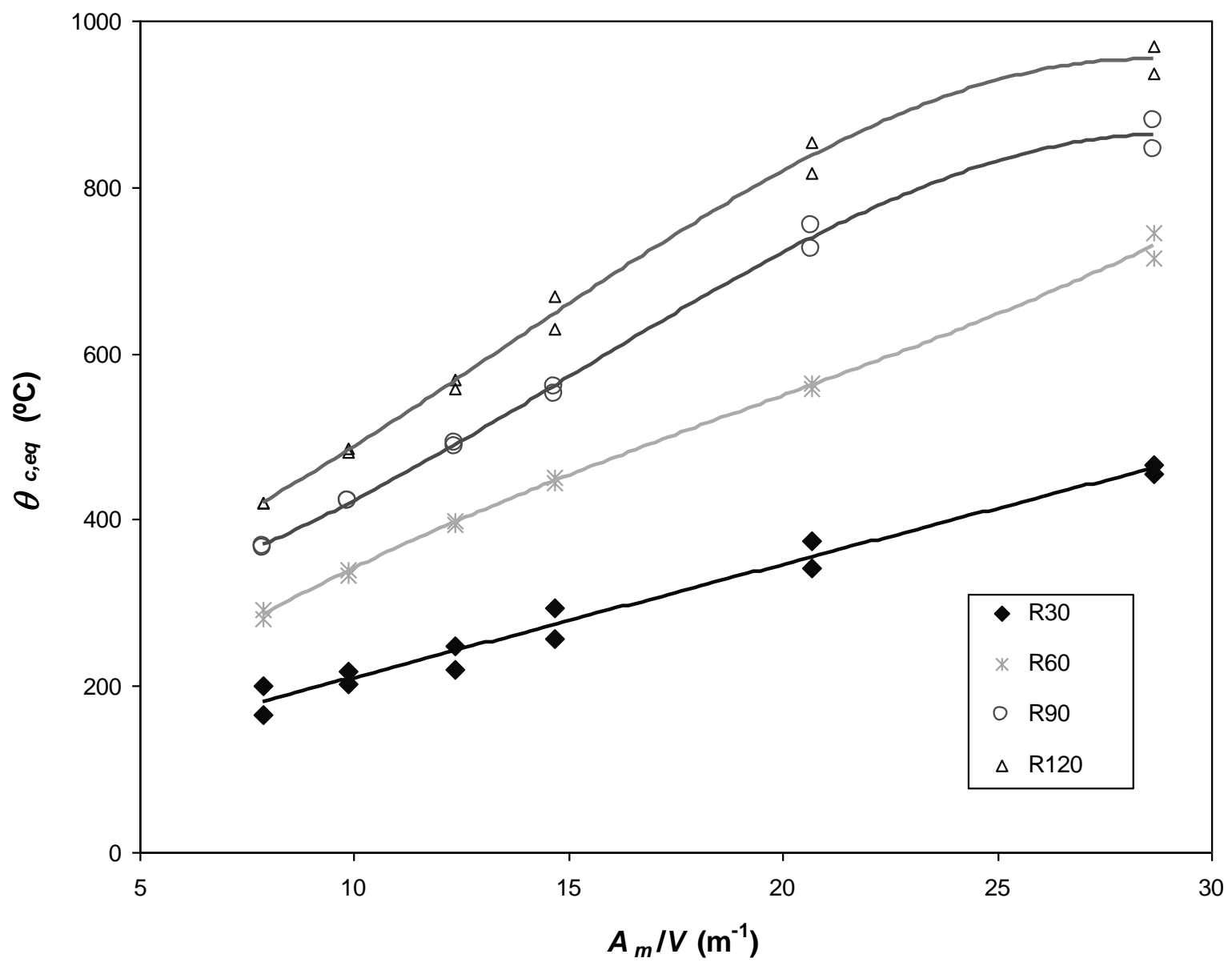

Fig. 6. Evolution of the equivalent temperature of the concrete core with the section factor, for the standard fire resistance classes. 
a)

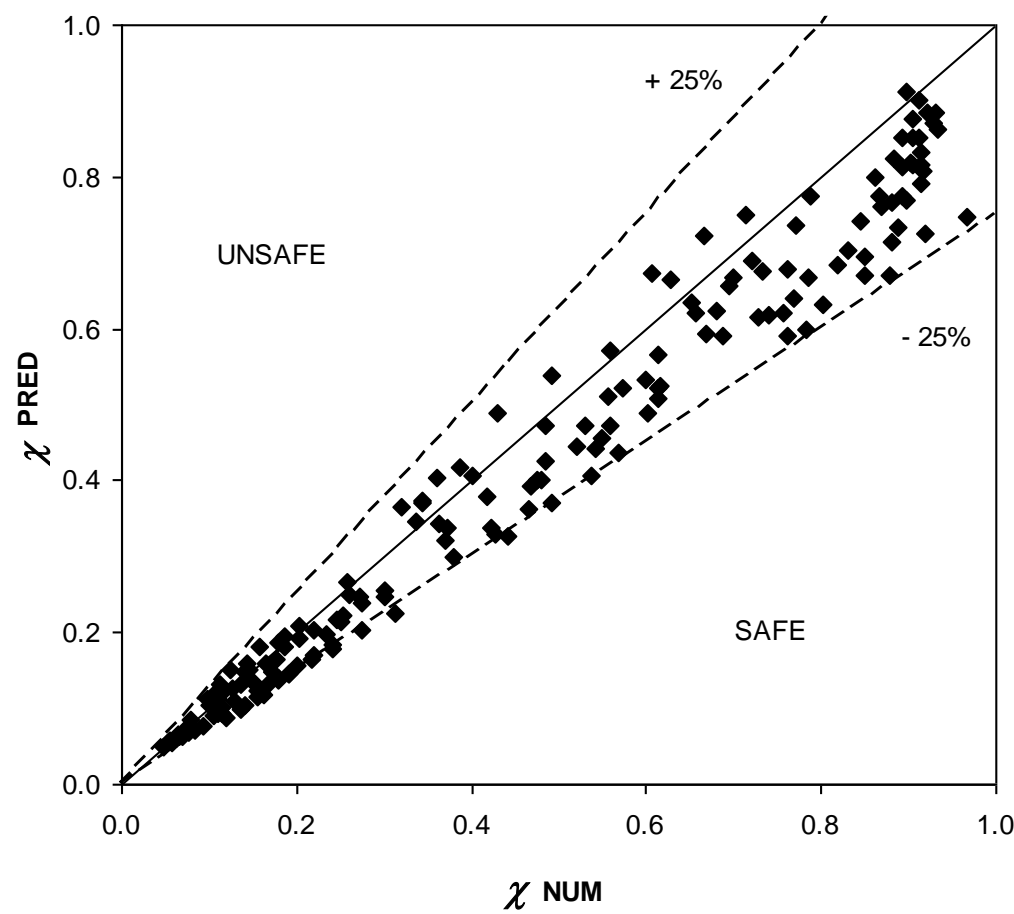

b)

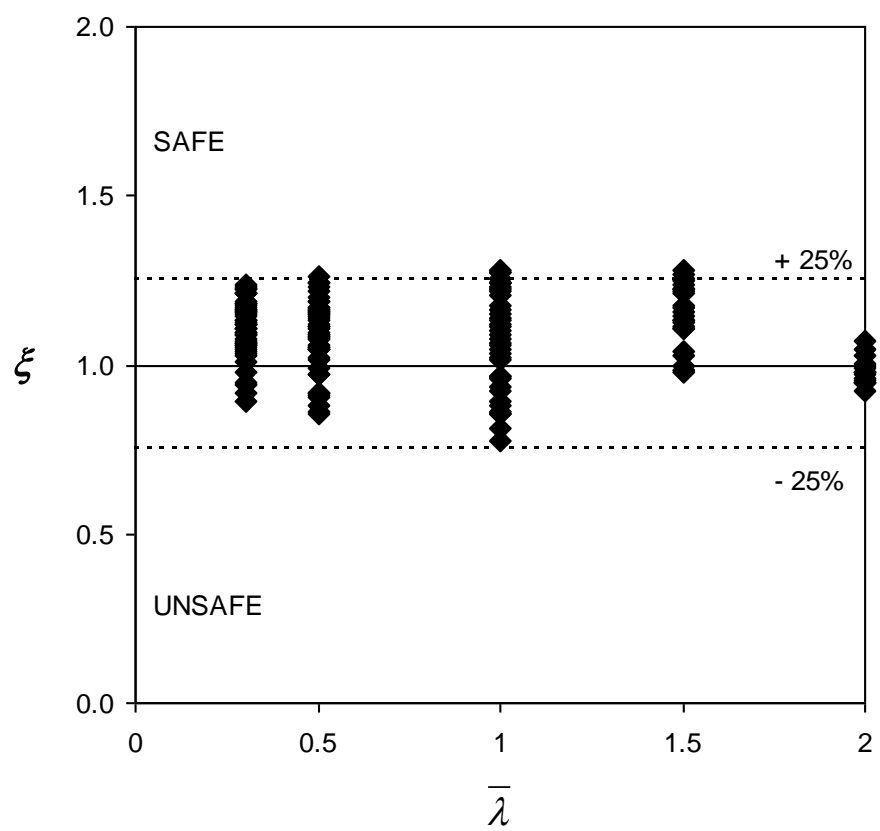

Fig. 7. Comparison between the proposed method and numerical simulations: a) Normalised buckling load, b) Relative error. 


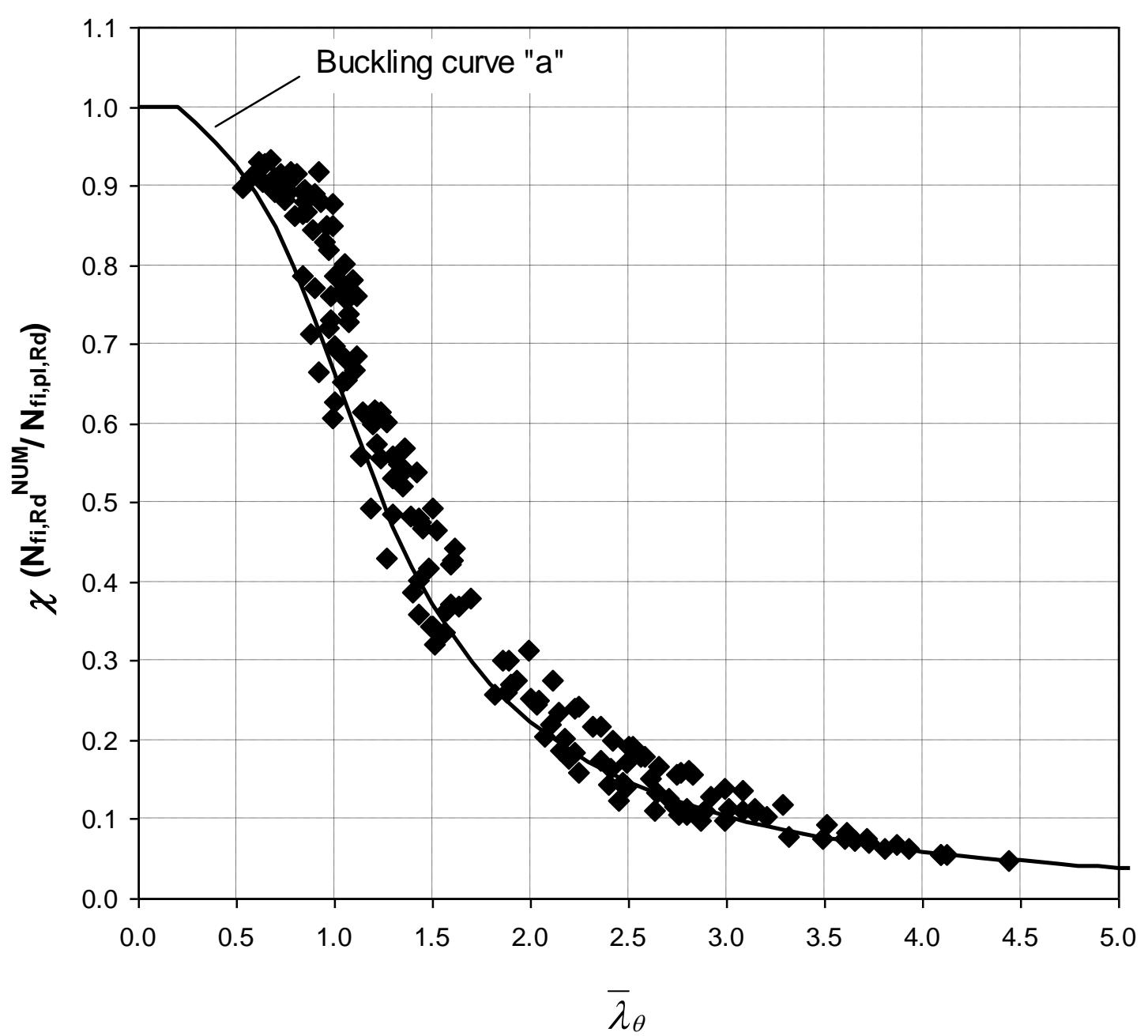

Fig. 8. Evolution of the buckling coefficient with the relative slenderness at elevated temperature, calculated with the proposed method. 
Espinos A, Romero ML, Hospitaler A. Simple calculation model for evaluating the fire resistance of unreinforced concrete filled tubular columns. Eng Struct. 2012;42:231-44. doi: 10.1016/j.engstruct.2012.04.022

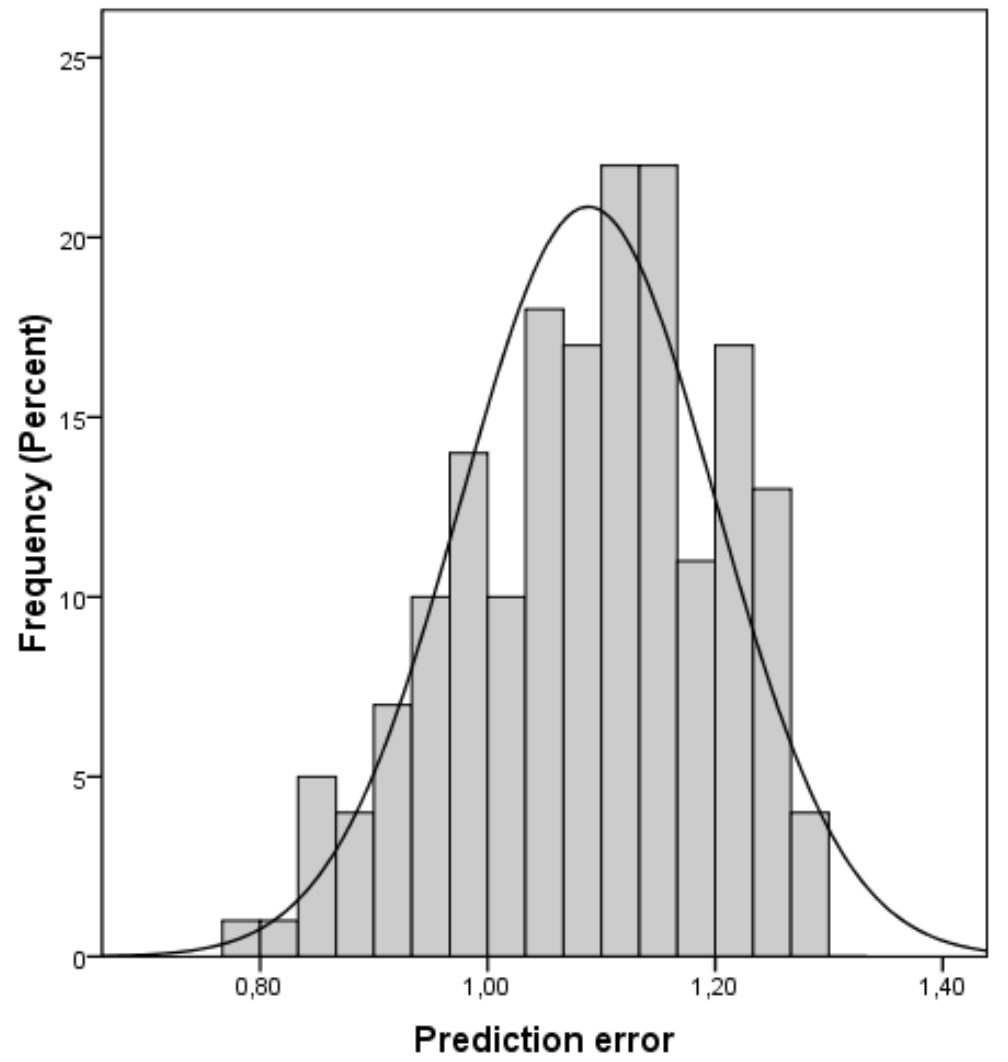

Fig. 9. Frequency histogram for the prediction error obtained with the proposed method. 


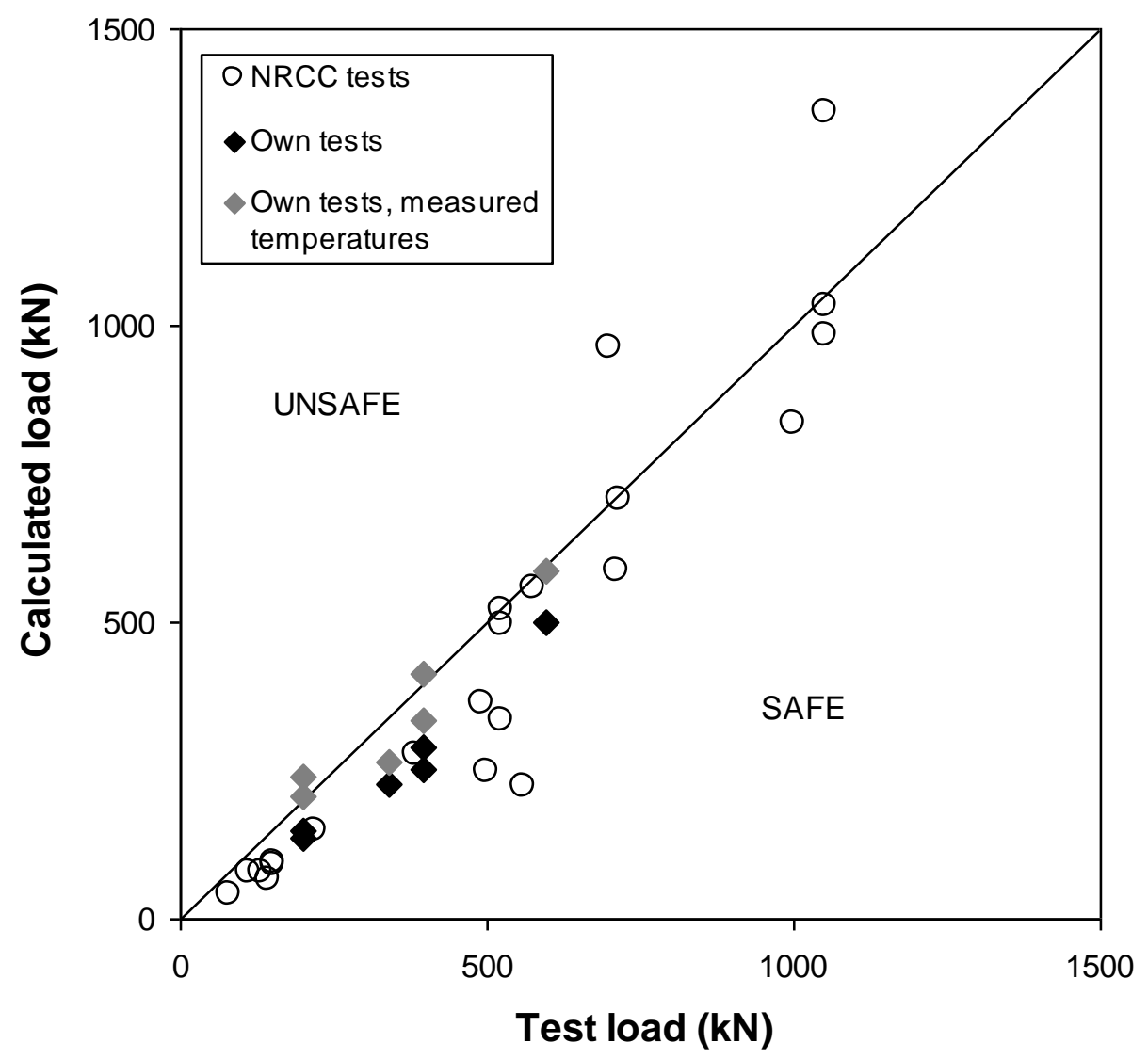

Fig. 10. Comparison of ultimate loads between the proposed method and tests. 


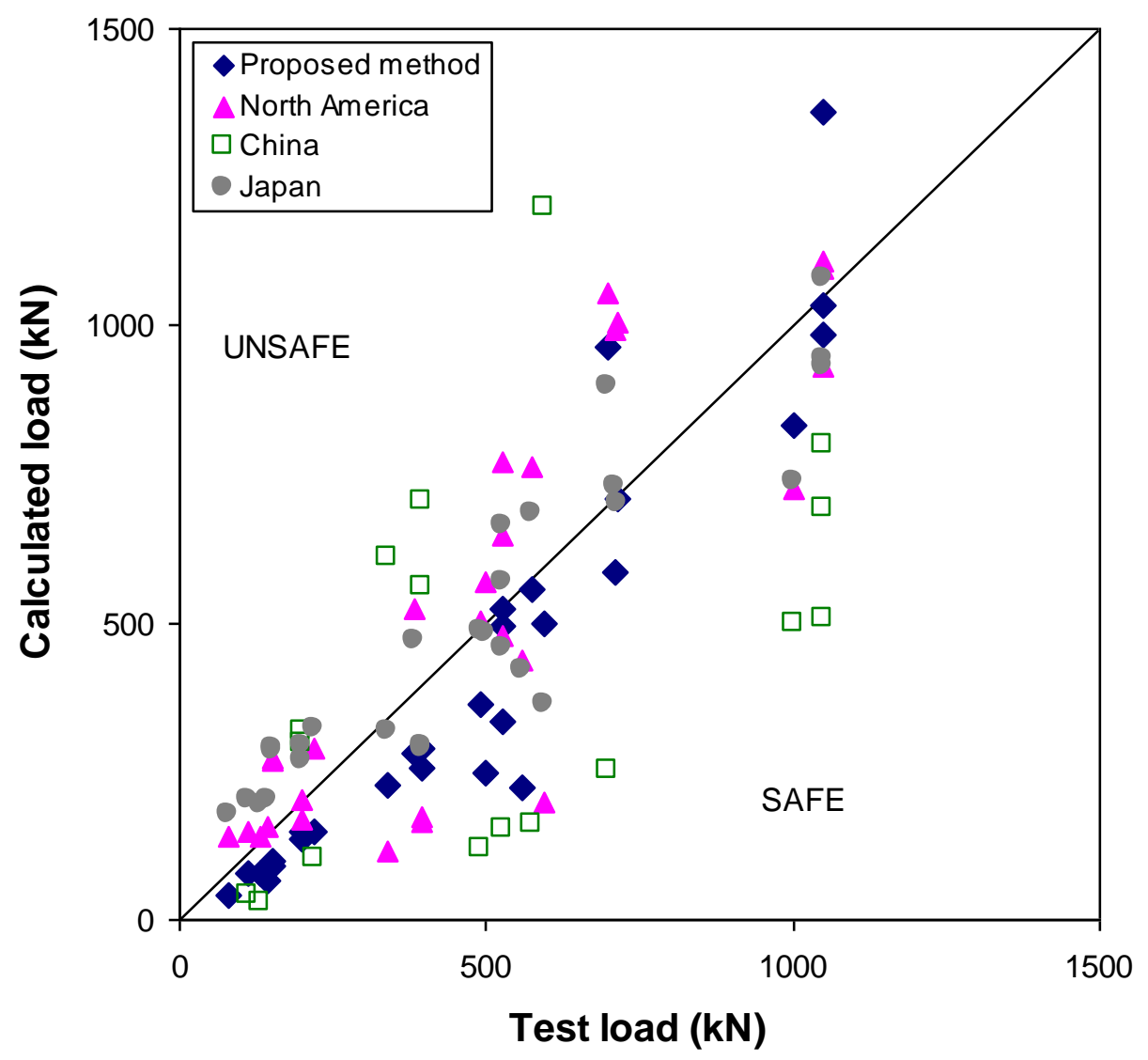

Fig. 11. Comparison of ultimate loads between the proposed method, other methods and tests. 
Table 1. Summary of the analysis cases in the parametric studies

\begin{tabular}{ccccccc}
\hline Variable & \multicolumn{5}{c}{ Specified values } \\
\hline$D(\mathrm{~mm})$ & 139.7 & 193.7 & 273 & 323.9 & 406.4 & 508 \\
$t(\mathrm{~mm})$ & $3.2 ; 12.5$ & $5 ; 16$ & $5 ; 16$ & $6.3 ; 16$ & $8 ; 16$ & $10 ; 16$ \\
$\bar{\lambda}$ & \multicolumn{5}{c}{$0.3 ; 0.5 ; 1 ; 1.5 ; 2$} \\
$R(\min )$ & $30 ; 60 ; 90 ; 120$ \\
\hline
\end{tabular}


Table 2. Values of the equivalent temperatures for concrete $\left(\theta_{c, e q}\right)$ and steel $\left(\theta_{a, e q}\right)$ in function of the section factor

\begin{tabular}{|c|c|c|c|c|c|c|c|c|c|}
\hline & \multicolumn{2}{|c|}{ R30 } & \multicolumn{2}{|c|}{ R60 } & \multicolumn{2}{|c|}{ R90 } & \multicolumn{2}{|c|}{ R120 } \\
\hline & & $\theta_{c, e q}\left({ }^{\circ} \mathrm{C}\right)$ & $\theta_{a, e q}\left({ }^{\circ} \mathrm{C}\right)$ & $\theta_{c, e q}\left({ }^{\circ} \mathrm{C}\right)$ & $\theta_{a, e q}\left({ }^{\circ} \mathrm{C}\right)$ & $\theta_{c, e q}\left({ }^{\circ} \mathrm{C}\right)$ & $\theta_{a, e q}\left({ }^{\circ} \mathrm{C}\right)$ & $\theta_{c, e q}\left({ }^{\circ} \mathrm{C}\right)$ & $\theta_{a, e q}\left({ }^{\circ} \mathrm{C}\right)$ \\
\hline \multirow{6}{*}{$\begin{array}{c}A_{m} / V \\
\left(\mathbf{m}^{-1}\right)\end{array}$} & 5 & 141 & 636 & 197 & 857 & 316 & 957 & 344 & 1013 \\
\hline & 10 & 210 & 652 & 342 & 869 & 422 & 964 & 487 & 1018 \\
\hline & 15 & 278 & 669 & 453 & 880 & 571 & 971 & 659 & 1024 \\
\hline & 20 & 346 & 686 & 549 & 891 & 721 & 978 & 819 & 1030 \\
\hline & 25 & 413 & 703 & 647 & 903 & 831 & 985 & 928 & 1035 \\
\hline & 30 & 480 & 719 & 764 & 914 & 860 & 992 & 947 & 1041 \\
\hline
\end{tabular}


Espinos A, Romero ML, Hospitaler A. Simple calculation model for evaluating the fire resistance of unreinforced concrete filled tubular columns. Eng Struct. 2012;42:231-44. doi: 10.1016/j.engstruct.2012.04.022

Table 3. Values of the partial reduction coefficient for steel $\varphi_{a, \theta 1}$ to include in the design equation for stocky columns $\left(\ell_{\theta} / D \leq 12\right)$

\begin{tabular}{cc}
\hline$D / t$ & $\varphi_{a, \theta 1}$ \\
\hline$<15$ & 0.75 \\
$15-35$ & 1 \\
$35-45$ & 1.25 \\
$>45$ & 2.5 \\
\hline
\end{tabular}


Table 4. Values of the reduction coefficient for steel $\varphi_{a, \theta}$ (tabulated method)

\begin{tabular}{|c|c|cccc|}
\cline { 3 - 6 } \multicolumn{2}{c|}{} & \multicolumn{4}{c|}{$A_{m} / V\left(\mathbf{m}^{-1}\right)$} \\
\cline { 3 - 6 }$\ell_{\theta} / D$ & $<\mathbf{1 0}$ & $\mathbf{1 0}-\mathbf{1 5}$ & $\mathbf{1 5}-\mathbf{2 0}$ & $>\mathbf{2 0}$ \\
\hline & $\leq \mathbf{1 2}$ & 0.4 & 0.35 & 0.3 & 0.25 \\
& $\mathbf{2 4}$ & - & 0.5 & 0.5 & 0.4 \\
& $\mathbf{3 6}$ & - & - & 0.7 & 0.7 \\
& $\mathbf{2 4 6}$ & - & - & - & 1 \\
\hline
\end{tabular}




\section{LIST OF FIGURE CAPTIONS}

Fig. 1. Finite element mesh of the model for one of the columns analysed.

Fig. 2. Process for obtaining the buckling resistance of the columns at the different standard fire periods.

Fig. 3. Evolution of the buckling coefficient with the relative slenderness at elevated temperature (neglecting the flexural stiffness reduction coefficients).

Fig. 4. Comparison between the different approaches studied in terms of the normalised buckling resistance: a) EC4(1), b) EC4(2), c) EC4(H), d) EC4(NF).

Fig. 5. Evolution of the prediction errors with the relative slenderness of the columns, for the different approaches studied: a) EC4(1), b) EC4(2), c) EC4(H), d) EC4(NF).

Fig. 6. Evolution of the equivalent temperature of the concrete core with the section factor, for the standard fire resistance classes.

Fig. 7. Comparison between the proposed method and numerical simulations: a) Normalised buckling load, b) Relative error.

Fig. 8. Evolution of the buckling coefficient with the relative slenderness at elevated temperature, calculated with the proposed method.

Fig. 9. Frequency histogram for the prediction error obtained with the proposed method.

Fig. 10. Comparison of ultimate loads between the proposed method and tests.

Fig. 11. Comparison of ultimate loads between the proposed method, other methods and tests. 


\section{LIST OF TABLE CAPTIONS}

Table 1. Summary of the analysis cases in the parametric studies

Table 2. Values of the equivalent temperatures for concrete $\left(\theta_{c, e q}\right)$ and steel $\left(\theta_{a, e q}\right)$ in function of the section factor

Table 3. Values of the partial reduction coefficient for steel $\varphi_{a, \theta 1}$ to include in the design equation for stocky columns $\left(\ell_{\theta} / D \leq 12\right)$

Table 4. Values of the reduction coefficient for steel $\varphi_{a, \theta}$ (tabulated method) 